\title{
Analysis and Classification of ERP Producers by Business Operations
}

\author{
Alen Jakupovic ${ }^{1}$, Mile Pavlic ${ }^{2}$ and Kresimir Fertalj ${ }^{3}$ \\ ${ }^{1}$ Bussines Department, Polytechnic of Rijeka, Croatia \\ ${ }^{2}$ Department of Informatics, University of Rijeka, Croatia \\ ${ }^{3}$ Faculty of Electrical Engineering and Computing, University of Zagreb, Croatia
}

Enterprise Resource Planning (ERP) represents a general business application software solution which is applicable in different business operations. Therefore, it covers areas which are common to a certain group of business operations (e.g. manufacturing, services, financial services, public services, etc.). However, business operations, no matter if they belong to the same or different group, have specific areas which are not supported in general ERP solutions. This paper attempts to reveal which business operations are supported by specialized ERP solutions, how to measure the size of specialized ERP producers, how many business operations are supported by ERP producers on average, and whether there are any classifications of ERP producers based on the number of supported business operations.

Keywords: business operation, business organization, ERP solution, verticalization of ERP solution, business operations classification

\section{Introduction}

Business organizations have two ways of acquiring an application software solution: developing a brand new application software solution customized to meet the needs of a given business organization, or purchasing an existing application software solution which was based on an existing business technology.

In the first case, business organizations get an application software solution that supports their very own business technology. However, two basic problems emerge here: first, the price of developing a customized application software solution (which is, therefore, unique) is typically high, and second, the possibility of improving business technology based on the business technology which served as a pattern for developing application software solution (which was probably the result of bestpractice method), does not exist.

In the second case, business organizations get an application software solution with business technology that differs from their own. This is why a business organization needs to either adjust its business technology to the application software solution, or adjust the application software solution to its business technology. It would be optimal to apply the changes in both areas i.e. change what is easier to change in business technologies, and change what is easier to change in application software solution [2].

One sort of existing application software solutions is the ERP solution. The producers of modern ERP solutions have reported the existence of business functional areas common to a certain group of business operations (e.g. manufacturing, service, financial services, public services, etc.). Due to that, general business application software has emerged. It is applicable to different business operations, being a general ERP solution. However, business operations, no matter if they belong to the same or different group, have specific areas which are not supported in general ERP solutions. In this case, the verticalization of ERP solutions is introduced. The verticalization of ERP solution can be defined as a process of expanding, modifying or adjusting the general ERP solution by enforcing specific qualities of a certain business operation. The result of this procedure is a specialized ERP solution which supports business processes of the given business operation. 
A few questions emerge. Which business operations are supported by a specialized ERP solution; how to measure the size of specialized ERP producers, on average - how many business operations do the producers of ERP solution support; and, are there any classifications of ERP producers based on the number of supported business operations?

This paper tries to answer the emerging questions through an analysis of global ERP market.

Existing ERP solutions analyses are based on surveys conducted on producers or end users, which contain the value of different ERP features. In this way, the producer provides data such as: the average solution implementation cost, the average number of users, the coverage of application areas, the coverage of a certain market segment, applied technology, etc. while the data collected from the end users show: stability, flexibility, security, documentation, adaptability of the ERP solution, the level of support, upgrade reliability, improvement continuity, return on investment, etc. (see also [1], [7], [8], [9] and [17]).

As opposed to existing ERP solutions analyses, which concentrate on features of ERP software, this paper presents an analysis where the data about an ERP solution is used in order to analyze business operations covered by specialized ERP software. Therefore, the primary concerns of the analysis are the features of business operations.

\section{Basic Concepts}

In order to conduct the analysis of business operations covered by specialized ERP solutions, it is important to define the basic terms considered in this article: business operation, business organization and ERP solution.

\subsection{Business Operation}

Business operation is the sum of all actions a business organization performs in order to create benefit, either directly (e.g. launching a product for sale) or indirectly (e.g. providing services - for instance, a consultant advising business organizations on improving their product). [4]

Since this definition applies solely to commercial business organizations, it needs to be partially extended to encompass the definition of business operation of a non-commercial business organization. Having that in mind, the final definition is: business operation is the sum of all actions a commercial business organization performs in order to create benefit; including the actions a non-commercial business organization performs in order to fulfill its mission.

A unique classification of business operations does not exist. Every classification is a reflection of specific needs it has to fulfill. For instance, in January 2001, the Global Industry Classification Standard (GICS) emerged, consisting of 10 areas, 23 industry groups, 59 industries and 122 sub-industries (see Table 1.). [10]

\begin{tabular}{|l|l|l|l|}
\hline Sector & Industry Group & Industry & Sub-industry \\
\hline \hline Energy & Energy & $\begin{array}{l}\text { Energy Equipment } \\
\text { \& Services }\end{array}$ & $\begin{array}{l}\text { Oil \& Gas Drilling } \\
\text { (Drilling contractors or owners of drilling rigs that } \\
\text { contract their services for drilling wells) }\end{array}$ \\
\cline { 3 - 4 } & & $\begin{array}{l}\text { Oil \& Gas Equipment \& Services } \\
\text { (Manufacturers of equipment, including drilling } \\
\text { rigs and equipment, and providers of supplies and } \\
\text { services to companies involved in the drilling, } \\
\text { evaluation and completion of oil and gas wells.) }\end{array}$ \\
\cline { 3 - 4 } & & $\begin{array}{l}\text { Oil, Gas \& Consumable } \\
\text { Fuels }\end{array}$ & $\begin{array}{l}\text { Integrated Oil \& Gas } \\
\text { (Integrated oil companies engaged in the } \\
\text { exploration \& production of oil and gas, as well as } \\
\text { at least one other significant activity in either } \\
\text { refining, marketing and transportation, or chemicals.) }\end{array}$ \\
\hline
\end{tabular}

Table 1. An example from the GICS. 


\begin{tabular}{|c|}
\hline A. AGRICULTURE, FORESTRY AND FISHING \\
\hline $\begin{array}{l}\text { 01 Crop and animal production, hunting and related service activities } \\
01.1 \text { Growing of non-perennial crops } \\
\text { 01.11 Growing of cereals (except rice), leguminous crops and oil seeds } \\
01.12 \text { Growing of rice }\end{array}$ \\
\hline B. MINING AND QUARRYING \\
\hline$\ldots$ \\
\hline C. MANUFACTURING \\
\hline
\end{tabular}

Table 2. An example from the EUROSTAT classification.

\begin{tabular}{|l|l|}
\hline SAP $[15]$ & Microsoft $[11]$ \\
\hline \hline Financial and Public Services & Education \\
Banking & Higher Education \\
Defense \& Security & Schools \\
Defense Logistics & Financial Services \\
Public Security & Banking \\
Healthcare & Capital Markets \\
Healthcare Providers & Insurance \\
Higher Education \& Research & Government \\
Insurance & Federal/National \\
Public Sector & State/Regional \\
Public Security & Healthcare \\
Manufacturing & Health Plans \\
Aerospace \& Defense & Providers \\
Aerospace and Defense Manufacturers & Hospitality \\
Airline Management & Life Sciences \\
MRO/M\&E Service Providers & Manufacturing \\
Automotive & Automotive \\
Automotive OEMs & Chemicals \\
Sales and Service Organizations & Consumer Packaged Goods \\
Automotive Suppliers & High Tech and Electronics \\
Chemicals & Oil and Gas \\
.. & . \\
\hline
\end{tabular}

Table 3. An example from the commercial classification of business operations according to SAP and Microsoft.

GICS has been created in order to answer the needs of the financial community for a complete, consistent representation of global areas and industry definitions. [10]

The Statistical Office of the European Communities (EUROSTAT) has developed a proprietary operations classification which it uses for different statistical research. EUROSTAT classification consists of 10 areas which are shown in detail through 5 levels at the most. (see Table 2.) $[5]$
Large-scale producers of business software applications (IBM, ORACLE, SAP, Microsoft) offer solutions adapted to different business operations, and due to that, they have developed their own commercial classifications. (see Table 3.).

Commercial classifications of business operations are first and foremost used to identify business operations which are supported by commercial software solutions. This paper uses commercial classifications as a basis for the synthesis of business operations classification. 


\subsection{Business Organization}

An organization is a system. Therefore, it has all the features of a system, such as: aims, inputs, outputs, a border, functions, processes, flows, structure, components, hierarchy, subsystems, equifinality, specialization, integration, resources, etc. [18].

An organization is “.... a deliberate association of people whose common goal is to fulfil certain tasks using suitable means and least possible effort in whichever area of social life." [13]. When business is seen as an area of social life, business organization emerges. A synonym for business organization would be organization of a company, a firm, an office. Earlier mentioned ERP support producers - IBM, ORACLE, SAP, Microsoft - are examples of real business organizations operating on global market.

Every real business organization can perform one or more business operations. The GICS positions business organizations into one class of business operations (i.e. sub-industries). If a business organization performs more than one business operation, the main business operation is chosen. An important factor influencing the choice of a business operation is the realized revenue of the observed operation, as well as the profit analysis and market perception of the business organization. [10]

\subsection{Enterprise Resource Planning (ERP)}

International Data Corporation (IDC) defines ERP solution as an application software support for at least three of the following four segments of business: [6]

- accounting

- manufacturing

- material management/distribution

- HR management, payroll

ERP solution is a business application software support applicable in different business operations representing the horizontal width of the solution. It has been noticed that there are similar business processes in different business operations, and it is the ERP solution that propagates the standardization of their execution. By adjusting, modifying or expanding a general
ERP solution using specific business processes of a certain business operation, the ERP solution becomes specialized. The procedure is also known as verticalization of the solution. Figure 1 illustrates the interrelationship of business operations and the ERP solution. The ellipses represent business operations, and the rectangle filled with diagonal lines represents an ERP solution.

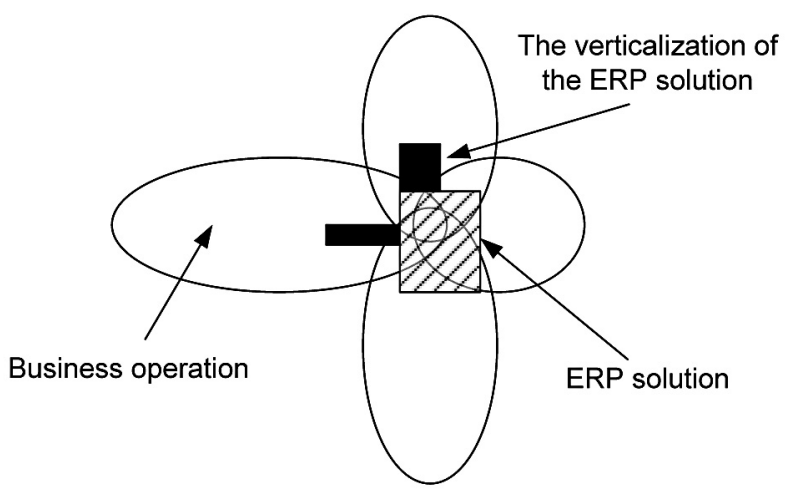

Figure 1. Interrelationship of business operation and an ERP solution.

The surface of ellipses represents a group of business processes which are performed within a business operation. Different surfaces denote different numbers of business processes. The overlapping of ellipses denotes the existence of same business processes which are performed in different business operations. The rectangle surface, filled with diagonal lines, represents business processes supported by an ERP solution. These business processes belong to different business operations, and from these facts stems the generality of ERP solution, i.e. its applicability to different business operations. To illustrate this, let us observe an example. An ERP solution, Microsoft Navision, can be applied to manufacturing business operations like food manufacturing, as well as to service operations like renting of construction machinery. The rectangle surface, filled with black colour, shows the expanding, adjusting or modifying of an existing ERP solution, which is specific for a given business operation, and is created through the process of verticalization of a general ERP solution. The result of the verticalization of a general ERP solution is the subject of analysis described in this paper. It needs to be mentioned that there are certain business operations not yet covered by specialized ERP solutions. However, it does not mean that there is 
no specific application software support to cover certain business processes of a given business operation (e.g. application software for health services), but such support, due to its features, does not belong to the class of ERP solutions. Such application software support is not the subject of analysis in this paper. Also, "Open Source" class of ERP solutions does not enter the analysis (i.e. ERP solutions which can be, after licensing, freely altered), such as: Adempiere, Compiere, ERP5, GNU Enterprise, OFBiz, Openbravo, TinyERP, WebERP, Pentaho. On "Open Source" application solutions see [3].

\section{The Analysis of Business Operations Covered by Specialized ERP Solutions}

The analysis further presented in this paper was conducted over 124 ERP solution producers. The list of producers emerged as a combination of other two main producers' lists, published on web pages of "On-line Consultant" (a list of 44 producers) [12] and "Quebec Inc." (a list of 97 producers) [14]. Operation of both these companies is the development of a method for choice of application software solutions. The
"Software Finder" [16] (a service for finding the producers of software solutions) was used to track down the official web pages of certain companies. Figure 2 shows the model which served as a basis for the analysis of ERP producers.

Out of 124 companies, six of them do not have an official web page, and a certain number of companies are part of other companies, and some companies are just vendors, offering ERP solutions by other producers (like SAP, Navision, etc). In effect, these companies were not considered. Finally, the number of analyzed companies offering their own ERP solution came to 91.

Existing classifications of business operations (e.g. GICS, EUROSTAT, etc.) are too extensive and too different to be used in the analysis of the size of specialized ERP producers based on the number of supported business operations; these have a different number of levels, are incomparable (business operation on one level in one classification does not exist in another classification, or is on a different level or bears a different name). Because of this, a new "General commercial classification of business operations" was developed; it is simpler, contains

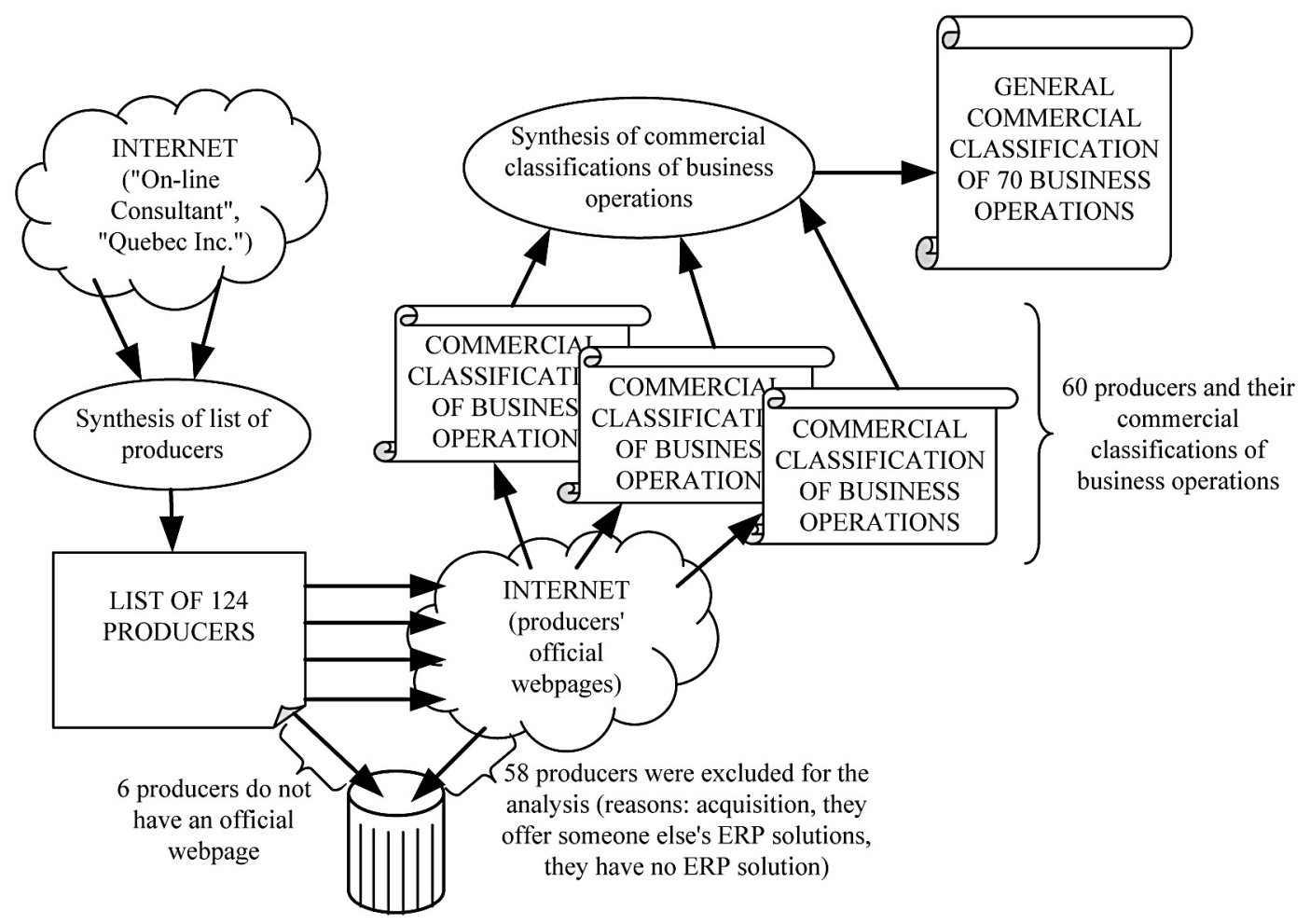

Figure 2. Model of the conducted ERP producers analysis. 
all supported business operations and as such, it is applicable to the comparison of the size of producers.

Out of 91 analyzed producers, 60 of them (i.e. $66 \%$ ) have a specialized ERP solution for a certain business operation. By analyzing commercial operations' classification of the given 60 producers and by their merging and aligning, a general commercial classification of ERP solution producers' business operations was formed.
A list of business operations for each and every producer was based on the data of supported business operations of every producer (the data used from their official web pages). Having performed the analysis of all producers, the resulting commercial classifications of business operations have been aligned in order to avoid overlapping. Table 4 shows an example of coordinating and merging two commercial classifications of business operations.

\begin{tabular}{|c|c|c|}
\hline SAP $[15]$ & Microsoft [11] & Coordinated and merged commercial classification \\
\hline Financial and Public Services & Education & Financial and Public Services \\
\hline Banking & Higher Education & Banking \\
\hline Defense \& Security & Schools & Capital Markets \\
\hline Defense Logistics & Financial Services & Insurance \\
\hline Public Security & Banking & Defense \& Security \\
\hline Healthcare & Capital Markets & Defense Logistics \\
\hline Healthcare Providers & Insurance & Public Security \\
\hline Higher Education \& Research & Government & Healthcare \\
\hline Insurance & Federal/National & Healthcare Payers \\
\hline Public Sector & State/Regional & Healthcare Providers \\
\hline Public Security & Healthcare & Education \& Research \\
\hline Manufacturing & Health Plans & Schools \\
\hline Aerospace \& Defense & Providers & Higher Education \\
\hline Aerospace and Defense Manufacturers & Hospitality & Research \\
\hline Airline Management & Life Sciences & Public Sector \\
\hline MRO/M\&E Service Providers & Manufacturing & Government \\
\hline Automotive & Automotive & Public Security \\
\hline Automotive OEMs & Chemicals & Manufacturing \\
\hline Sales and Service Organizations & Consumer Packaged & Aerospace \& Defense \\
\hline Automotive Suppliers & Goods & Aerospace and Defense Manufacturers \\
\hline Chemicals & High Tech and & Airline Management \\
\hline Consumer Products & Electronics & MRO/M\&E Service Providers \\
\hline Food & Oil and Gas & Automotive \\
\hline Beverage & Utilities & Automotive OEMs \\
\hline Home and Personal Care & Media and Entertainment & Sales and Service Organizations \\
\hline Consumer Durables and Home Appliances & Professional Services & Automotive Suppliers \\
\hline Apparel and Footwear & Retail & Chemicals \\
\hline Engineering, Construction \& Operations & Service Providers & Consumer Products \\
\hline High Tech & & Apparel and Footwear \\
\hline Business, Medical, and Consumer OEMs & & Beverage \\
\hline Electronics Manufacturing Service Providers & & Consumer Durables and Home Appliances \\
\hline Semiconductor and Component & & Food \\
\hline Manufacturers & & Home and Personal Care \\
\hline Software Providers & & Engineering, Construction \& Operations \\
\hline Industrial Machinery \& Components & & High Tech \\
\hline Life Sciences & & Business, Medical, and Consumer OEMs \\
\hline Pharmaceuticals & & Electronics Manufacturing Service Providers \\
\hline Biotechnology/Biopharmaceuticals & & Semiconductor and Component Manufacturers \\
\hline Medical Device/Scientific Instruments & & Software Providers \\
\hline
\end{tabular}




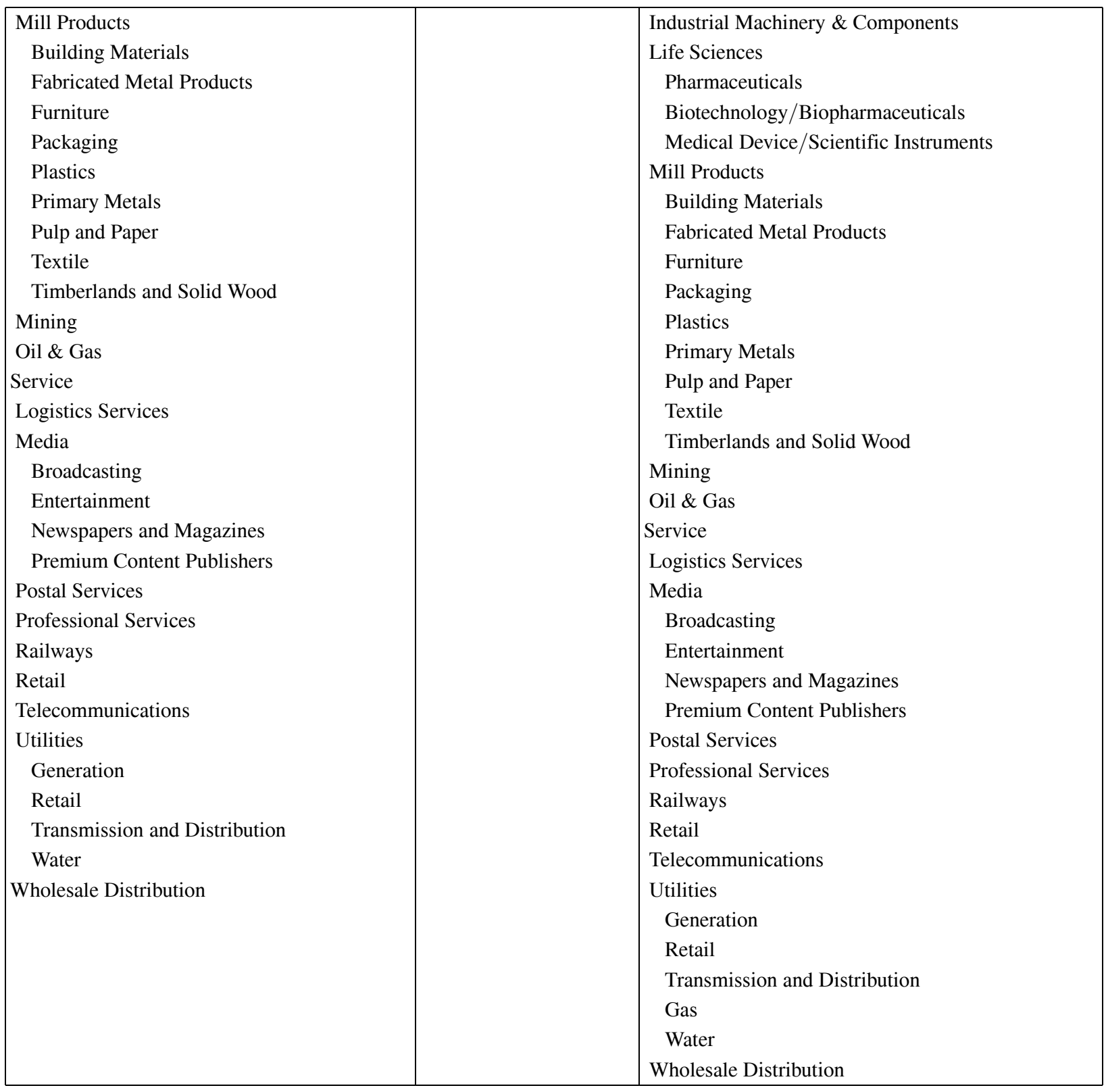

Table 4. Coordinating and merging two commercial classifications of business operations.

Finally, these were integrated into a final list. In this way, a final list emerged, showing 70 business operations to which specialized ERP solutions can be applied. (see Table 5.).

The analysis of commercial classifications of ERP solutions producers resulted in three basic classes of business operations: financial and public services (12 basic business operations) manufacturing (35 basic business operations) and services (23 basic business operations). The results of the conducted analysis and synthesis of data from Table 11, 12 and 13 (see appendix) are shown in Table 6. The most producers ( 43 of them, i.e. $72 \%$ of all producers) offer specialized ERP solutions for up to 10 business operations, but none of them covers all operations. On average, every ERP solution producer covers around 10 business operations. In the fourth column of Table 6 , the width of business operations that certain producers of ERP solutions cover is shown, i.e. the average of supporting the overall number of business operations. 


\begin{tabular}{|c|c|c|}
\hline Financial and Public Services & Manufacturing & Service \\
\hline $\begin{array}{l}\text { 1. Banking } \\
\text { 2. Capital Markets } \\
\text { 3. Insurance } \\
\text { Defense \& Security } \\
\text { 4. Defense Logistics } \\
\text { 5. Public Security } \\
\text { Healthcare } \\
\text { 6. Healthcare Payers } \\
\text { 7. Healthcare Providers } \\
\text { Education \& Research } \\
\text { 8. Schools } \\
\text { 9. Higher Education } \\
\text { 10. Research } \\
\text { Public Sector } \\
\text { 11. Government } \\
\text { 12. Public Security }\end{array}$ & $\begin{array}{l}\text { Aerospace \& Defense } \\
\text { 13. Aerospace and Defense } \\
\text { Manufacturers } \\
\text { 14. Airline Management } \\
\text { 15. MRO/M\&E Service Providers } \\
\text { Automotive } \\
\text { 16. Automotive OEMs } \\
\text { 17. Sales and Service Organizations } \\
\text { 18. Automotive Suppliers } \\
\text { 19. Chemicals } \\
\text { 20. Shipbuilding } \\
\text { 21. Agricultural } \\
\text { Consumer Products } \\
\text { 22. Apparel and Footwear } \\
\text { 23. Beverage } \\
\text { 24. Consumer Durables and Home } \\
\text { Appliances } \\
\text { 25. Food } \\
\text { 26. Home and Personal Care } \\
\text { 27. Engineering, Construction \& } \\
\text { Operations } \\
\text { High Tech } \\
\text { 28. Business, Medical, and Consumer } \\
\text { OEMs } \\
\text { 29. Electronics Manufacturing Service } \\
\text { Providers } \\
\text { 30. Semiconductor and Component } \\
\text { Manufacturers } \\
\text { 31. Software Providers } \\
\text { 32. Industrial Machinery \& Components } \\
\text { Life Sciences } \\
\text { 33. Pharmaceuticals } \\
\text { 34. Biotechnology/Biopharmaceuticals } \\
\text { 35. Medical Device/Scientific Instruments } \\
\text { Mill Products } \\
\text { 36. Building Materials } \\
\text { 37. Fabricated Metal Products } \\
\text { 38. Furniture } \\
\text { 39. Packaging } \\
\text { 40. Plastics } \\
\text { 41. Primary Metals } \\
\text { 42. Pulp and Paper } \\
\text { 43. Textile } \\
\text { 44. Rubber } \\
\text { 45. Timberlands and Solid Wood } \\
\text { 46. Mining } \\
\text { 47. Oil \& Gas }\end{array}$ & $\begin{array}{l}\text { 48. Logistics Services } \\
\text { Media } \\
\text { 49. Broadcasting } \\
\text { 50. Entertainment } \\
\text { 51. Newspapers and Magazines } \\
\text { 52. Premium Content } \\
\text { Publishers } \\
\text { 53. Postal Services } \\
\text { 54. Professional Services } \\
\text { 55. Railways } \\
\text { 56. Marine Transportation } \\
\text { 57. Retail } \\
\text { 58. Facilities Management } \\
\text { 59. Not for Profit \& Charities } \\
\text { 60. Rental } \\
\text { 61. Hospitality } \\
\text { 62. Real Estate } \\
\text { 63. Telecommunications } \\
\text { Utilities } \\
\text { 64. Generation } \\
\text { 65. Retail } \\
\text { 66. Transmission and } \\
\text { Distribution } \\
\text { 67. Gas } \\
\text { 68. Waste } \\
\text { 69. Water } \\
\text { 70. Wholesale Distribution }\end{array}$ \\
\hline
\end{tabular}

Table 5. General commercial classification of business operations. 


\begin{tabular}{|c|c|c|c|c|}
\hline Number & Producer & $\begin{array}{c}\text { Number of supported } \\
\text { business operations }\end{array}$ & \% of supporting & $\begin{array}{l}\text { Number of different } \\
\text { business operations }\end{array}$ \\
\hline 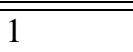 & Add+On Software & 1 & 1.43 & \multirow{50}{*}{$\begin{array}{l}\text { Small-size producers } \\
57(81 \%)\end{array}$} \\
\hline 2 & Datacor & 1 & 1.43 & \\
\hline 3 & Evolucion e Inovacion Empresarial SC & 1 & 1.43 & \\
\hline 4 & GMA Infosys & 1 & 1.43 & \\
\hline 5 & iLatina B2B Business Services & 1 & 1.43 & \\
\hline 6 & iSoft & 1 & 1.43 & \\
\hline 7 & MYOB US & 1 & 1.43 & \\
\hline 8 & Red Wing Software, Inc. & 1 & 1.43 & \\
\hline 9 & Advanced Software Development Corp & 2 & 2.86 & \\
\hline 10 & American Business Systems, Inc. & 2 & 2.86 & \\
\hline 11 & CYMA & 2 & 2.86 & \\
\hline 12 & Verticent & 2 & 2.86 & \\
\hline 13 & Cougar Mountain Software & 3 & 4.29 & \\
\hline 14 & eTek International & 3 & 4.29 & \\
\hline 15 & IQMS & 3 & 4.29 & \\
\hline 16 & Maconomy, Inc & 3 & 4.29 & \\
\hline 17 & Tailor Made Systems (TMS) & 3 & 4.29 & \\
\hline 18 & Vigilant Business Software, Inc. & 3 & 4.29 & \\
\hline 19 & $3 \mathrm{i}$ Infotech & 4 & 5.71 & \\
\hline 20 & Datamodes & 4 & 5.71 & \\
\hline 21 & EXEControl Global Solutions & 4 & 5.71 & \\
\hline 22 & Open System, Inc & 4 & 5.71 & \\
\hline 23 & Relevant Business Systems & 4 & 5.71 & \\
\hline 24 & BatchMaster Software Inc & 5 & 7.14 & \\
\hline 25 & EMR Innovations & 5 & 7.14 & \\
\hline 26 & Intacct Corp & 5 & 7.14 & \\
\hline 27 & Deltek Systems & 6 & 8.57 & \\
\hline 28 & FlexiInternational & 6 & 8.57 & \\
\hline 29 & Intuit & 6 & 8.57 & \\
\hline 30 & JDH Business Systems & 6 & 8.57 & \\
\hline 31 & ProfitKey International & 6 & 8.57 & \\
\hline 32 & CSB-System & 7 & 10.00 & \\
\hline 33 & Enhanced Systems \& Services & 7 & 10.00 & \\
\hline 34 & Glovia International & 7 & 10.00 & \\
\hline 35 & NetSuite & 7 & 10.00 & \\
\hline 36 & Sage Software & 7 & \begin{tabular}{|l|l|}
10.00 \\
10.00
\end{tabular} & \\
\hline 37 & Cedar Group & 8 & 11.43 & \\
\hline 38 & Epicor & 8 & 11.43 & \\
\hline 39 & Europa Telecom Group & 8 & \begin{tabular}{|l|l|}
11.43 \\
11.43
\end{tabular} & \\
\hline 40 & Made2Manage Systems & 8 & 11.43 & \\
\hline 41 & Ceecom, Inc. & 9 & 12.86 & \\
\hline 42 & Cincom Systems & 10 & 14.29 & \\
\hline 43 & COSS Systems & 10 & 14.29 & \\
\hline 44 & CMS Manufacturing Systems, Inc & 12 & 17.14 & \\
\hline 45 & Ross Systems & 12 & 17.14 & \\
\hline 46 & Technology Group International & 12 & 17.14 & \\
\hline 47 & QAD & 13 & 18.57 & \\
\hline 48 & Ramco Systems & 13 & 18.57 & \\
\hline 49 & Mincom & 14 & 20.00 & \\
\hline 50 & $\mathrm{i} 2$ & 15 & 21.43 & \\
\hline
\end{tabular}




\begin{tabular}{|c|c|c|c|c|}
\hline 51 & Eshbel & 20 & 28.57 & \multirow{8}{*}{$\begin{array}{l}\text { Middle-size producers } \\
58(83 \%)\end{array}$} \\
\hline 52 & SYSPRO & 21 & 30.00 & \\
\hline 53 & Microsoft & 29 & 41.43 & \\
\hline 54 & IFS & 30 & 42.86 & \\
\hline 55 & IFS & 30 & 42.86 & \\
\hline 56 & Intentia International & 31 & 44.29 & \\
\hline 57 & Aperum (novo ime infor) & 32 & 45.71 & \\
\hline 58 & IBM & 39 & 55.71 & \\
\hline 59 & Oracle & 54 & 77.14 & \multirow{2}{*}{$\begin{array}{l}\text { Large-scale producers } \\
61(87 \%)\end{array}$} \\
\hline 60 & SAP & 56 & 80.00 & \\
\hline
\end{tabular}

Table 6. Number of business operations supported by producers of ERP solution.

Until now, a comparison has not been conducted of a large number of ERP producers based on an exact specification of business operations which these support, with the assumption that the weight factor of every business operation is the same. Measuring weight factors of business operations demands additional research. The result is a measure of the size of a certain specialized ERP solution under the assumption that one producer has one ERP solution. This measure marks the diversity of the ERP solution with regard to the support of different business operations. The sum of this diversity is the total size of specialized, currently applicable ERP solutions. The size is expressed in the number of business operations these solutions cover. The analysis has shown that this number is 70 .

The question is how to classify the producers of ERP solutions by the number of business operations they cover. One solution is to observe the distribution of ERP solution producers with respect to the average of supporting business operations. (see Figure 3).

Figure 3 shows that the distribution of the number of ERP producers creates three basic classes (classes are circled in the figure): Class I small-size, Class II - middle-size and Class III - large-scale producers of ERP solutions (see Table 7). Borders of some classes can be defined as an arithmetic mean between the last average of supporting in the current class and the first average in the following class. The resulting average represents the top border of the first class. Therefore, the last average of Class I is $22 \%$, and the first average of Class II is $29 \%$.

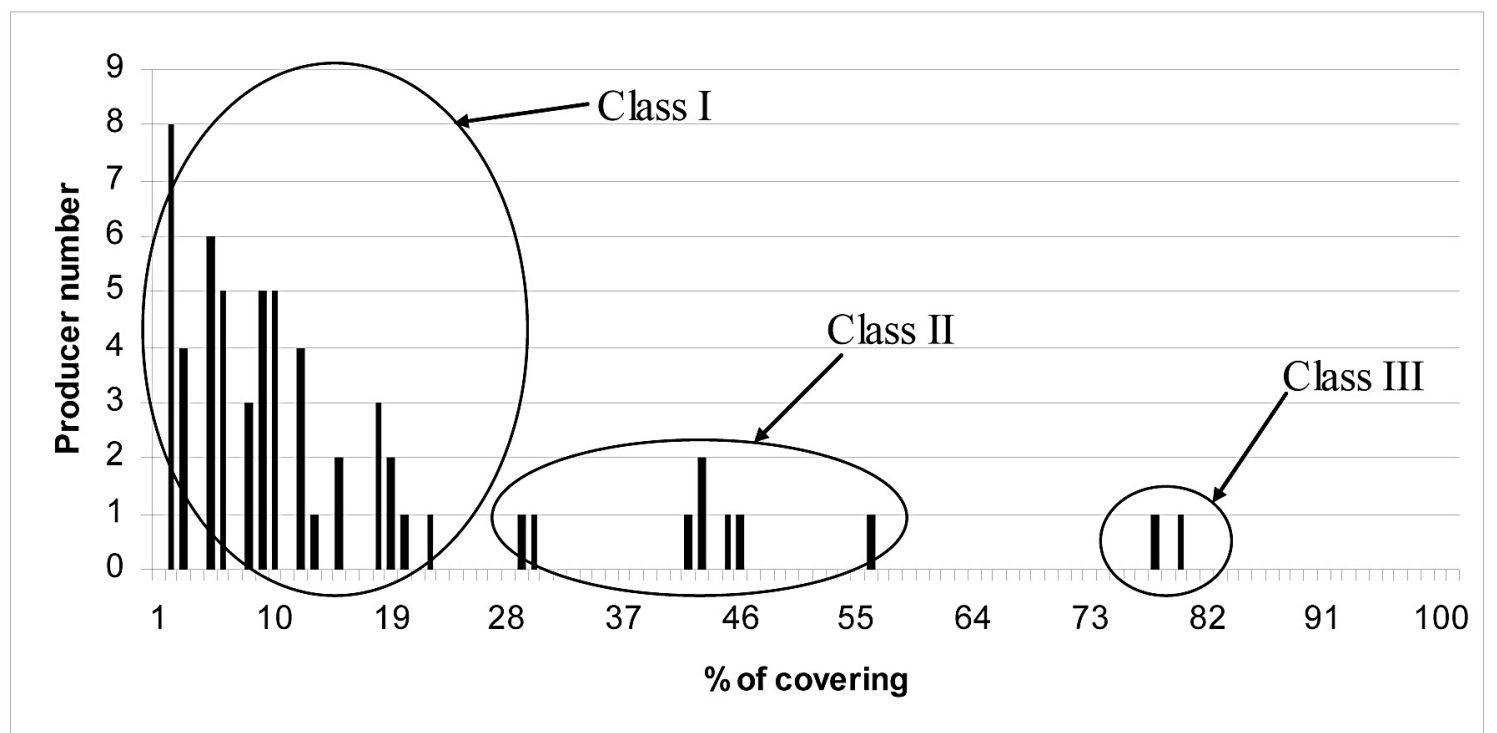

Figure 3. Distribution of the number of ERP producers. 
The arithmetic mean is $(22+29) / 2 \approx 26$, so the top border of Class I is 26\%. By analogy, the last average of Class II is $56 \%$, the first average of Class III is $78 \%$, the arithmetic mean is $(56+78) / 2=67$, so the top border of Class II is $67 \%$ of supporting. Table 7 shows the definitions of class borders, and a suggestion for the terminology.

\begin{tabular}{|l|l|l|}
\hline Class & Class term & $\begin{array}{c}\text { Border of supporting } \\
\text { business operations }\end{array}$ \\
\hline \hline I & Small-size producers & $1 \%-26 \%$ \\
\hline II & Middle-size producers & $27 \%-67 \%$ \\
\hline III & Large-scale producers & $68 \%-100 \%$ \\
\hline
\end{tabular}

Table 7. Definitions of class borders.

The last column in Table 6 shows the number of different business operations covered by all ERP producers of the observed class. Class "small-size producers" covers 57 basic business operations listed in the general commercial classification (see Table 5). Therefore, the ERP producers of the class "small-size producers" cover $81 \%$ of the general commercial classification of business operations. By analogy, class "middle-size producers", which consists of 8 ERP producers, covers 58 basic business operations. Finally, class "large-size producers", consisting of 2 ERP producers, covers 61 basic business operations, i.e. $87 \%$ of general commercial classification.

The least number of covered business operations supported by an ERP producer is 1, where the largest number is 56 .
The analysis on specialized ERP solution support of business operations shows that there are a relatively small number of producers that support almost every business operation listed in the general commercial classification. Also, the average of supporting is almost constant throughout the classes of ERP solution producers.

Figure 4 illustrates the total number of business operations in relation to ERP solution producers.

The white column on Figure 4 represents the total number of different business operations covered by all producers of a given class.

Table 8, consisting of two columns, was composed to serve the needs of performing the regression analysis. The first column shows the ERP producer numbers, and the second column shows the percentage of covering the total number of business operations. Table row shows how many ERP producers cover the total number of business operations represented in a certain percentage. The percentage of covering is defined using the fourth column in Table 6 , and the number of ERP producers represents the total number of producers from Table 6 which have the observed percentage. The regression analysis was performed using a software SPSS 12.0 .

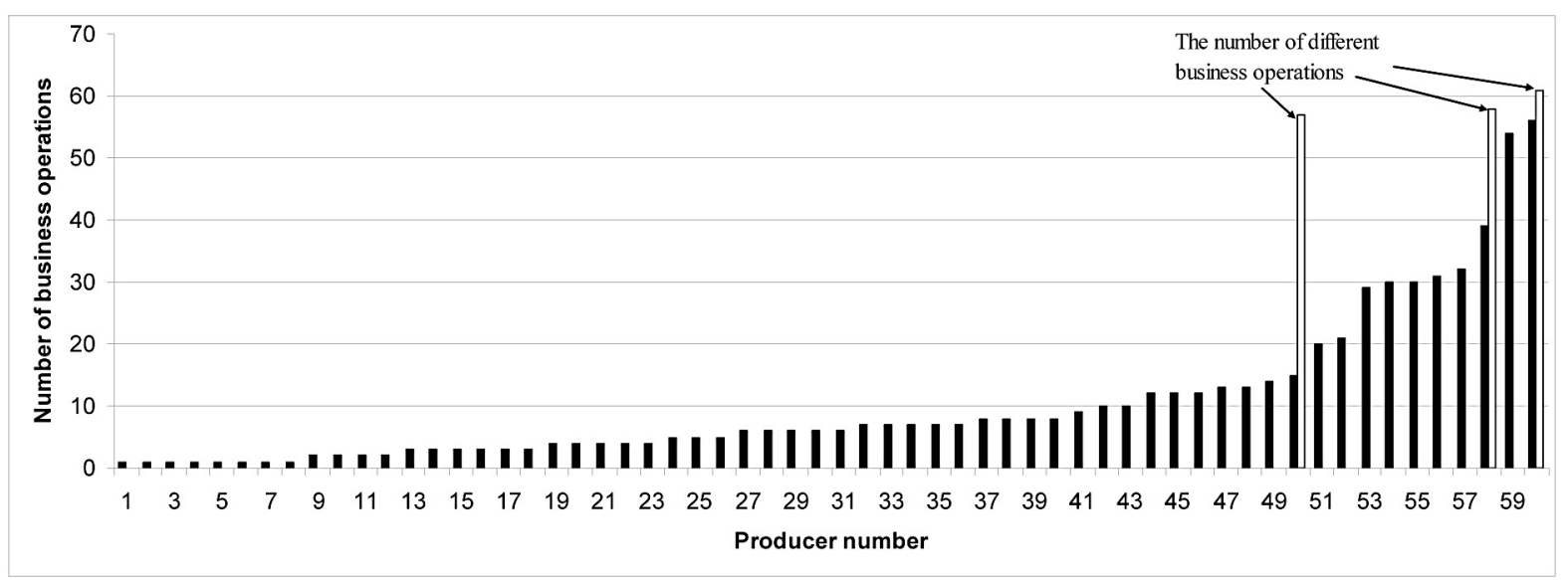

Figure 4. Graphic representation of the total number of business operations in relation to ERP solution producers. 


\begin{tabular}{|l|l|}
\hline Number of ERP producer & \% of covering \\
\hline \hline 8 & 1.43 \\
\hline 4 & 2.86 \\
\hline 6 & 4.29 \\
\hline 5 & 5.71 \\
\hline 3 & 7.14 \\
\hline 5 & 8.57 \\
\hline 5 & 10.00 \\
\hline 4 & 11.43 \\
\hline 1 & 12.86 \\
\hline 2 & 14.29 \\
\hline 3 & 17.14 \\
\hline 2 & 18.57 \\
\hline 1 & 20.00 \\
\hline 1 & 21.43 \\
\hline 1 & 28.57 \\
\hline 1 & 30.00 \\
\hline 1 & 41.43 \\
\hline 2 & 42.86 \\
\hline 1 & 44.29 \\
\hline 1 & 45.71 \\
\hline 1 & 55.71 \\
\hline 1 & 77.14 \\
\hline 1 & 80.00 \\
\hline
\end{tabular}

Table 8. Number of ERP producers sorted by the percentage of covering the total number of business operations.

The number of ERP producers was used as criteria, while the percentage of covering served as predictor. The scatter diagram of ERP producers by the percentage of covering the total number of business operations (Figure 5) shows a nonlinear negative co-varying of the percentage of covering and ERP producers. As the percentage of covering the total number of business operations increases, the number of ERP producers decreases.

Using the software SPSS 12.0, ten different regression models ( shown in Table 9) were analysed.

\begin{tabular}{|c|c|}
\hline Model name & Equation \\
\hline Linear & $y=\beta_{0}+\beta_{1} x$ \\
\hline Logarithmic & $y=\beta_{0}+\beta_{1} \ln (x)$ \\
\hline Inverse & $y=\beta_{0}+\frac{\beta_{1}}{x}$ \\
\hline Quadratic & $y=\beta_{0}+\beta_{1} x+\beta_{2} x^{2}$ \\
\hline Cubic & $y=\beta_{0}+\beta_{1} x+\beta_{2} x^{2}+\beta_{3} x^{3}$ \\
\hline Power & $\begin{array}{c}y=\beta_{0} x^{\beta_{1}} \text { or } \\
\ln (y)=\ln \left(\beta_{0}\right)+\beta_{1} \ln (x)\end{array}$ \\
\hline Compound & $\begin{array}{c}y=\beta_{0} \beta_{1}^{x} \text { or } \\
\ln (y)=\ln \left(\beta_{0}\right)+\ln \left(\beta_{1}\right) x\end{array}$ \\
\hline S-curve & $\begin{array}{c}y=e^{\left(\beta_{0}+\frac{\beta_{1}}{x}\right)} \text { or } \\
\ln (y)=\beta_{0}+\left(\frac{\beta_{1}}{x}\right)\end{array}$ \\
\hline Growth & $\begin{array}{c}y=e^{\left(\beta_{0}+\beta_{1} x\right)} \text { or } \\
\ln (y)=\beta_{0}+\beta_{1} x\end{array}$ \\
\hline Exponential & $\begin{aligned} y & =\beta_{0} e^{\beta_{1} x} \text { or } \\
\ln (y) & =\ln \left(\beta_{0}\right)+\beta_{1} x\end{aligned}$ \\
\hline
\end{tabular}

Table 9. List of analysed regression models.

Table 10 shows concise results of the analysis of ten different regression models. The following values are shown: the correlation coefficient $(R)$, the coefficient of determination $\left(R^{2}\right)$, standard error of regression $\left(\sigma_{Y}\right)$, the variation coefficient of regression $\left(\mathrm{V}_{\mathrm{Y}}\right)$, and parameters $\beta_{0}, \beta_{1}, \beta_{2}$ and $\beta_{3}$.

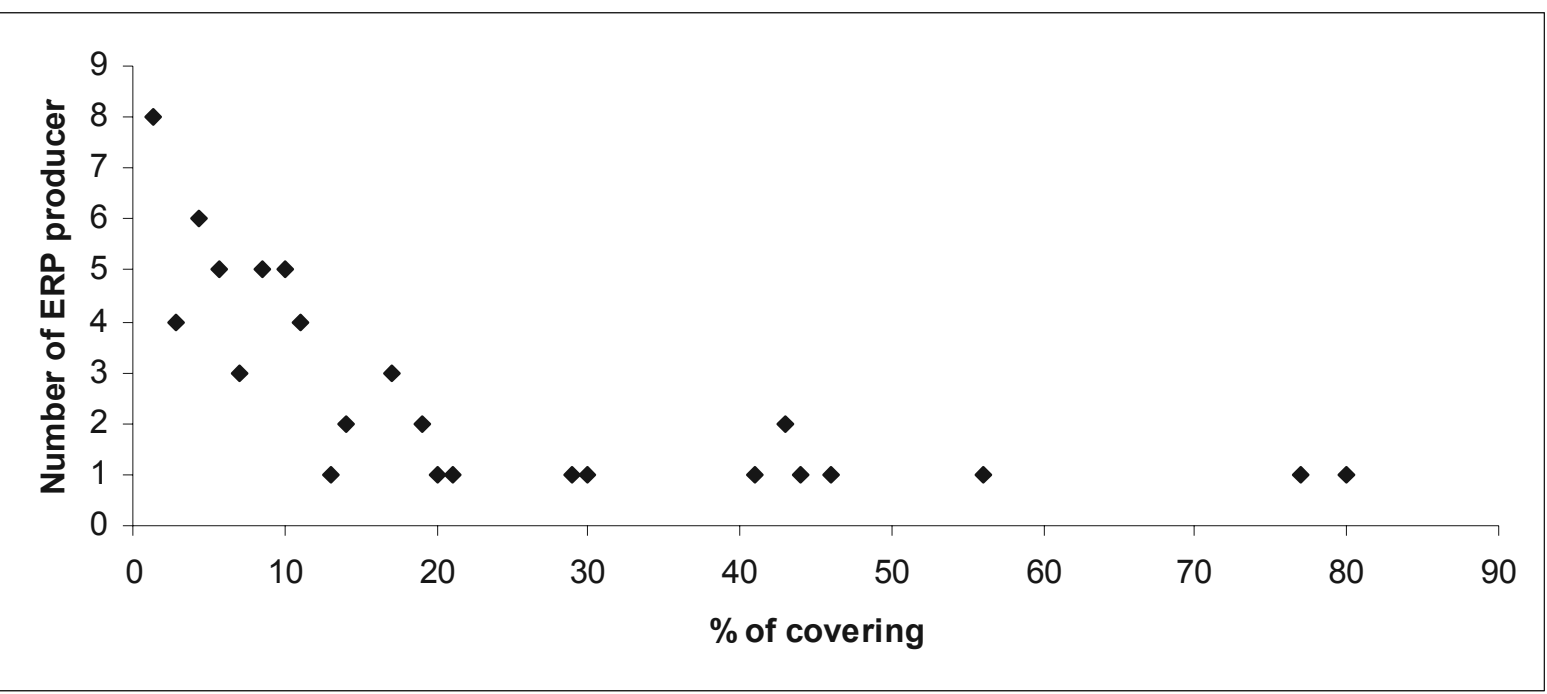

Figure 5. The scatter diagram of the number of ERP producers by the percentage of covering. 


\begin{tabular}{|l|l|l|l|l|l|l|l|l|}
\hline $\begin{array}{l}\text { Model } \\
\text { name }\end{array}$ & $\mathrm{R}$ & $\mathrm{R}^{2}$ & $\sigma_{\mathrm{Y}}$ & $\mathrm{V}_{\mathrm{Y}}$ & $\beta_{0}$ & $\beta_{1}$ & $\beta_{2}$ & $\beta_{3}$ \\
\hline \hline Linear & -0.65982 & 0.43536 & 1.56832 & $60.12 \%$ & 4.158913 & -0.059284 & & \\
\hline Logarithmic & -0.86100 & 0.74132 & 1.06153 & $40.69 \%$ & 7.319259 & -1.664424 & & \\
\hline Inverse & -0.80805 & 0.65294 & 1.22956 & $47.13 \%$ & 1.451227 & 10.814466 & & \\
\hline Quadratic & -0.82646 & 0.68303 & 1.20408 & $46.16 \%$ & 5.710246 & -0.205722 & 0.001936 & \\
\hline Cubic & -0.89127 & 0.79436 & 0.99504 & $38.14 \%$ & 7.211646 & -0.458088 & 0.010307 & -0.00006983644 \\
\hline Power & -0.84773 & 0.71865 & 0.40463 & $15.51 \%$ & 10.803938 & -0.598973 & & \\
\hline Compound & -0.70704 & 0.49990 & 0.53947 & $20.68 \%$ & 3.639626 & 0.977049 & & \\
\hline S-curve & -0.69761 & 0.48666 & 0.54656 & $20.95 \%$ & 0.319495 & 3.412455 & & \\
\hline Growth & -0.70704 & 0.49990 & 0.53947 & $20.68 \%$ & 1.291881 & -0.023219 & & \\
\hline Exponential & -0.70704 & 0.49990 & 0.53947 & $20.68 \%$ & 3.639626 & -0.023219 & & \\
\hline
\end{tabular}

Table 10. Concise results of regression analysis.

The concise results of regression analysis (Table 10) illustrate that the Cubic model shows the largest factor of correlation which is -0.89127 , and this leads to the existence of a strong nonlinear connection between the number of ERP producers and the percentage of covering. The existence of a strong connection between the number of ERP producers and the percentage of covering, i.e. the fact that the percentage of covering determines the number of ERP producers which belong to the class that is defined by the percentage of covering, justifies classifying ERP producers through the number of supported business operations.

The Cubic model has a high percentage of interpreted total variations of the number of ERP producers by the percentage of covering the total number of business operations $\left(\mathrm{R}^{2}=0.79436\right.$, which results in $79.44 \%$ of interpretations). However, this model has a relatively high coefficient of regression variation $\left(V_{Y}\right)$, from which it follows that the deviation of the real from the expected number of ERP producers by the percentage of covering the total number of business operations, is $38.14 \%$.

The Power model has the least coefficient value of the regression variation $\left(\mathrm{V}_{\mathrm{Y}}\right)$, and its deviation from the real number of ERP producers is $15.51 \%$. However, in relation to the $\mathrm{Cu}$ bic model, it has a somewhat lower percentage of interpreted total variations of the number of ERP producers by the percentage of covering the total number of business operations.

For Cubic and Power models, Table 10 illustrates that the parameters $\beta_{2}$ and $\beta_{3}$ (quadratic and cubic component in the model) have a relatively small individual contribution to the expla- nation of co-varying the percentage of covering and the number of ERP producers. A question emerges: are these components statistically significant, i.e. can these be generalized to a wider population or they are just accidental? The answer to this question demands further research.

It cannot be unequivocally said which model is more representational. Figure 6 illustrates the relationship of the number of ERP producers by the percentage of covering and the diagram of the Cubic model.

It is visible that the Cubic model forecasts negative values of the number of ERP producers for certain percentages of covering business operations, which is impossible in the real world. However, this model suggests the non-existence of ERP producers which cover the total number of business operations in a high percentage. Therefore, the model suggests not to expect ERP producers which cover over $84 \%$ of total number of business operations.

The Cubic model supposes three different variation dynamics of the number of ERP producers by the percentage of covering. From $1 \%$ to $34 \%$ of covering, the number of ERP producers rapidly decreases. From $35 \%$ to $71 \%$ of covering, the model implies a slow increase in the number of ERP producers, and from $72 \%$ a rapid decrease, all up to $84 \%$, where ERP producers are no longer expected. The percentage intervals of which limits are determined by specific variation dynamics of the number of ERP producers $(1 \%-34 \%, 35 \%-71 \%$, and $72 \%-100 \%)$ are similar to suggested intervals for the classification of ERP producers in Table 7. 


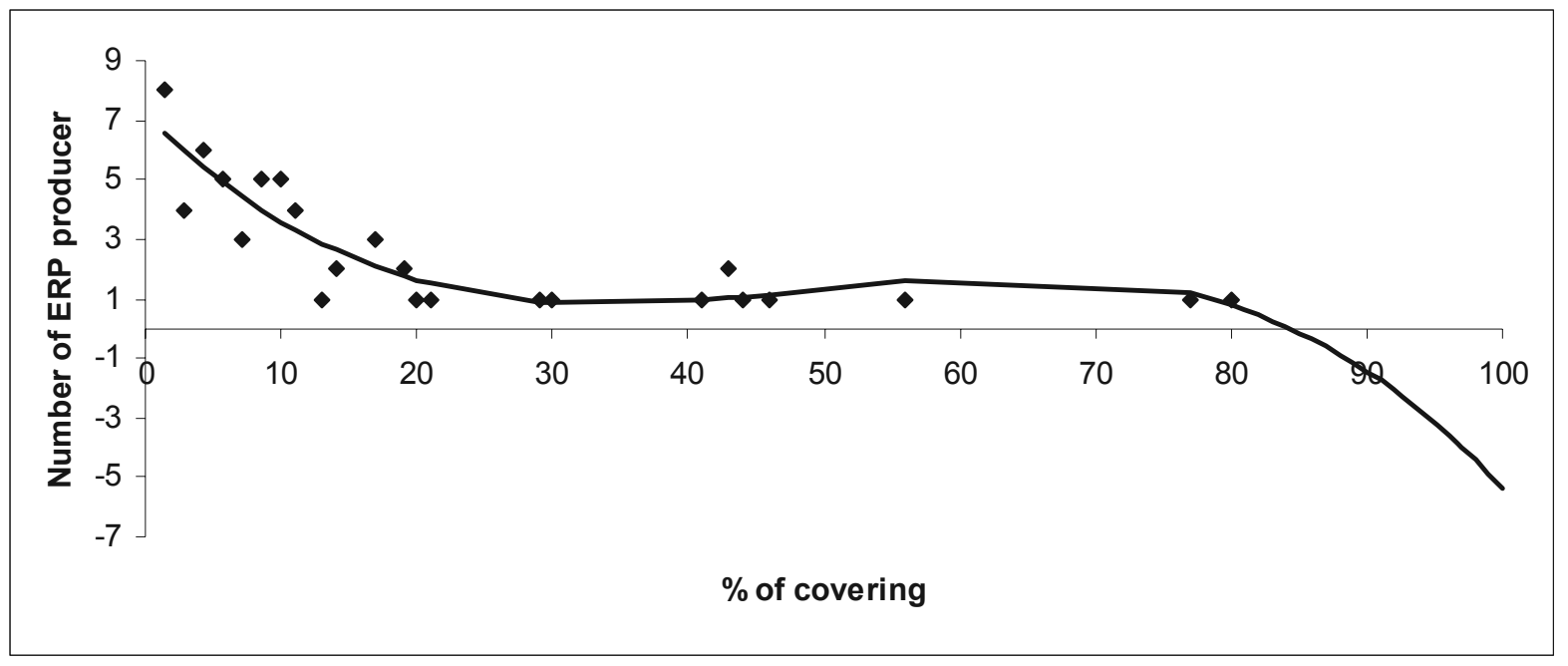

Figure 6. The relationship of the number of ERP producers by the percentage of covering and the diagram of the Cubic model.

Figure 7 illustrates the relationship of the number of ERP producers by the percentage of covering and the diagram of the Power model. The Power model does not forecast negative values of the number of ERP producers. Therefore, it suggests the existence of ERP producers even at the highest percentages of covering the total number of business operations. Finally, it also suggests the existence of ERP producers which cover all business operations. In a real-world scenario, it is hard to expect the existence of an ERP producer whose ERP solution would cover all business operations.

The Power model implies the existence of two different variation dynamics of the number of ERP producers by the percentage of covering. It can be seen that for the initial growth of the percentage of covering (up to $40 \%$ ) the number of ERP producers rapidly decreases, and after that point, the decrease assumes almost a linear form. In conclusion, this model suggests classifying ERP producers into two classes.

It is possible to conduct further research which would show how the support of ERP producers from the last class with most operations has grown over time, and determine the speed of the growth. This could be used as a prediction of growth of certain solutions. The creation of new ERP solutions or the evolution of certain software into ERP solutions is expected and probable. One should also consider the existence of ERP solutions which were unavailable to the authors for this research.

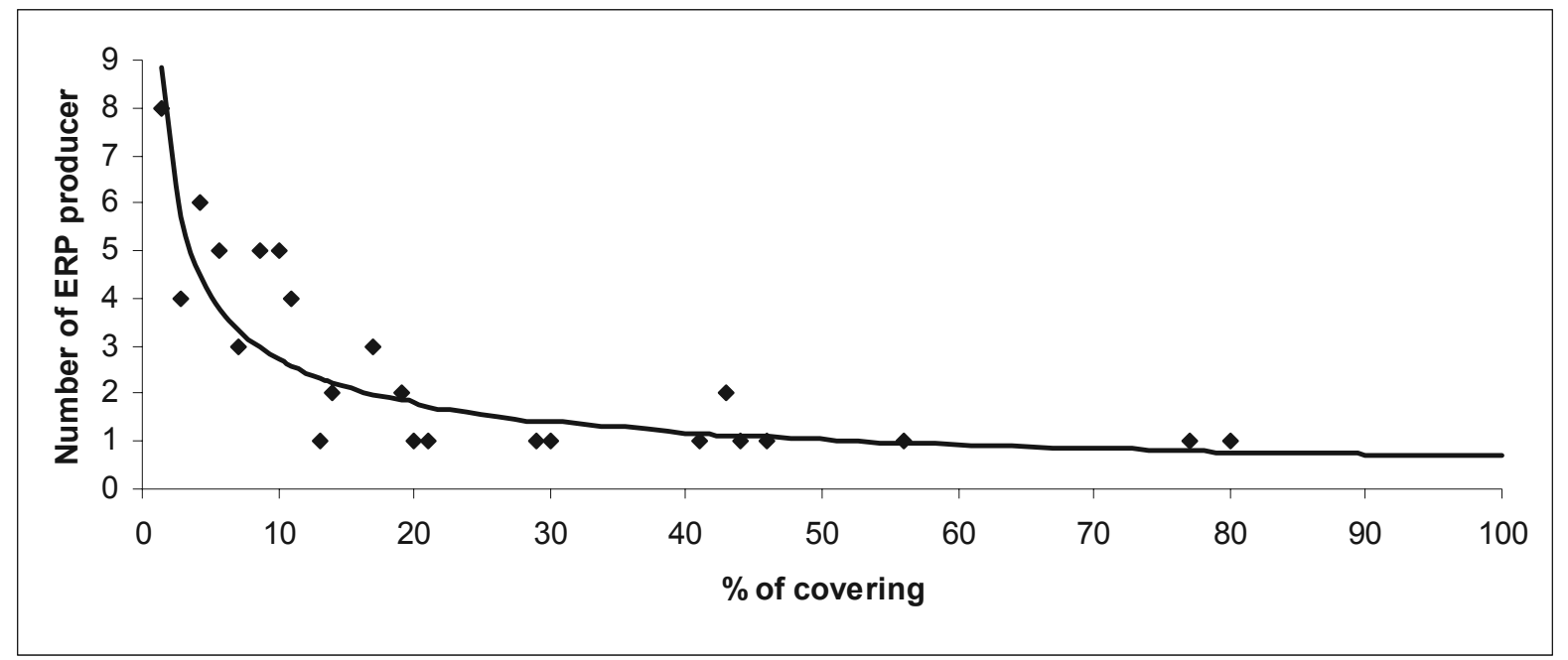

Figure 7. The relationship of the number of ERP producers by the percentage of covering and the diagram of the Power model. 


\section{Conclusion}

The results of the conducted analysis show varying range of supporting business operations by specialized ERP solutions. The range depends on the ERP producer, as well as on business operation. In the decision making process, the ERP producers mostly base their selection on economic profitability, which includes the analysis of the market needs for such a solution, as well as investments required for the development of the solution. It is during the estimation of investment that the complexity of business processes within a business operation is considered.

It is worth noting that the analysis does not penetrate the depth of a certain business operation support, like which processes are supported, and which are not supported by the solution, to what extend the support goes, etc. For such an indepth analysis, specific functionalities of particular specific add-ons of ERP solution should be considered. Such an analysis would most certainly strengthen the estimation of the level of supporting business operations by application software solution.

The paper analyzed specific software support for different business operations which represent an add-on to ERP solutions. Therefore, it analyzed ERP producers and suggested their classification based on the average of supporting business operations. It was possible to create a linear classification of ERP producers, but the analysis of business operations support has shown that these tend to group into three relatively stable classes. Even though the possibility that an ERP producer transfers from a higher class to a lower one exists, under the condition that a number of business operations not supported by a producer emerges, the probability of such a situation is extremely low. This would lead to monopolistic producers. On the other hand, the transfer of an ERP producer to a higher class demands extraordinary financial resources, time and know-how for specific business technology, because new business operations need support.

The suggested classification of ERP producers has shown that there are a small number of producers in the highest class (two of them), i.e. most ERP producers are specialized in fewer business operations. The question is whether it is better to be in a lower or higher class and how this affects the features of the business application software support, like the level of supporting business operations, the level of reliability of software support, etc.

The regression analysis has shown two regression models (Cubic and Power). The Cubic model has the highest percentage of interpreted variations of the number of ERP producers by the percentage of covering, as well as proportionally high percentage of deviation. On the other hand, the Power model has a proportionally smaller percentage of interpretation, but also the least percentage of deviation. Authors of this paper hold that the Cubic model is more representative for two basic reasons: the model does not suggest the existence of ERP producers which cover business operations in a high percentage, what is more likely in a real-world scenario (unlike the Power model which suggests the existence of ERP producer covering all business operations); and the model suggests the existence of three classes of ERP producers based on the percentage of covering the total number of business operations, what is also suggested by the distribution of the number of ERP producers (the Power model, on the other hand, suggests two classes).

It needs to be mentioned that this paper didn't consider producers offering exclusively specialized application software support, e.g. for banking, health, insurance, etc. If these producers were included in the analysis, an absolute level of supporting business operations by application software support would be reached, and not just the relative one, i.e. the level of supporting from the viewpoint of ERP solution producers.

Along with the existing list of business operations which are supported by ERP producers, business organizations have the possibility to see whether a specialized ERP solution already exists for their business operation, which can serve as additional information in the process of decision making concerning the acquisition of a new business application software solution. Also, the information on the existence of application software solution for a certain business operation can be of meaning in reaching the final decision on the choice of business operation a business organization will undertake in the process of foundation. 
On the other hand, such information can help the existing, as well as the future ERP producers, choose the business operation they will support.

Finding out which business operations are supported by specialized ERP solutions, a set of new questions emerge for the scientific community, such as: which factors influence the lack of support for certain business operations, which factors influence the dynamics of spreading the support to new business operations, do some business operations stand out in relation to the number of different specialized ERP solutions which support them, etc.

The distribution of knowledge, based on ERP producers, about certain business operations, provides business organizations with additional information on ERP producers, which can be used in the process of decision making concerning the choice of producer and its software support. It is possible that it would be better to leave the acquisition of software support to a producer which is specialized in a certain business operation, because this means that the producer is better acquainted with the business technology of a given business operation. However, this should not be the sole criterion in making the choice.

To ERP producers, either the existing ones or the new ones, the distribution of knowledge provides insight into the "encumbrance" under which ERP producers operate. The information on the encumbrance of existing ERP producers can serve as a guideline to existing or new producers, telling them how much knowledge they must have to enter the market. It is obvious that the analysis of entering the market cannot be based solely on such information.
Through the distribution of knowledge, the scientific community gets an insight into the "encumbrance" of ERP producer, as well as a set of new questions: which factors influence the encumbrance of ERP producers; factors of increase, decrease or invariability of encumbrance, is there a relationship between observed factors, what is the dynamics of this encumbrance, etc.

The "encumbrance" of specialized ERP producers stemmed from the problem of measuring their size. The size of ERP producers can be measured in different ways. One of the ways is to measure the level of market presence expressed in the number of certain producers' customers, or in the number of specialized ERP users of a given ERP producer. Another way is to measure the amount of the total revenue of producers which was the result of selling specialized ERP solutions. All these measures show the success of producers on a certain market. The area of interest here is the size of producers, but from the viewpoint of business operations, i.e. the size of specialized ERP producers from the viewpoint of supported business operations.

\section{Appendix}

Tables 11, 12 and 13 show the data which were used in the analysis of ERP producers by business operations. The first column shows producer's name, and other columns show numerical codes of certain business operations from the general commercial classification. 


\begin{tabular}{|c|c|c|c|c|c|c|c|c|c|c|c|c|c|}
\hline \multirow{2}{*}{ Producer } & \multicolumn{12}{|c|}{ Financial and Public Services } & \multirow{2}{*}{ TOTAL } \\
\hline & 1 & 2 & 3 & 4 & 5 & 6 & 7 & 8 & 9 & 10 & 11 & 12 & \\
\hline 3i Infotech & $\sqrt{ }$ & $\sqrt{ }$ & $\sqrt{ }$ & & & & & & & & $\sqrt{ }$ & & 4 \\
\hline Add+On Software & & & & & & & & & & & & & 0 \\
\hline Advanced Software Development Corp & & & & & & & & & & & & & 0 \\
\hline American Business Systems, Inc. & & & & & & & & & & & & & 0 \\
\hline Aperum & $\sqrt{ }$ & $\sqrt{ }$ & $\sqrt{ }$ & & & & & & & & $\sqrt{ }$ & & 4 \\
\hline BatchMaster Software Inc & & & & & & & & & & & & & 0 \\
\hline Cedar Group & $\sqrt{ }$ & & $\sqrt{ }$ & & & & $\sqrt{ }$ & & & & $\sqrt{ }$ & & 4 \\
\hline Cincom Systems & $\sqrt{ }$ & & $\sqrt{ }$ & & & $\sqrt{ }$ & $\sqrt{ }$ & $\sqrt{ }$ & $\sqrt{ }$ & & $\sqrt{ }$ & & 7 \\
\hline CMS Manufacturing Systems, Inc & & & & & & & & & & & & & 0 \\
\hline COSS Systems & & & & & & & & & & & 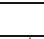 & & 0 \\
\hline Cougar Mountain Software & & & & & & & & & & & $\sqrt{ }$ & & 1 \\
\hline CSB-System & & & & & & & & & & & & & 0 \\
\hline CYMA & & & & & & & & & & & $\sqrt{ }$ & & 1 \\
\hline Datacor & & & & & & & & & & & & & 0 \\
\hline Datamodes & & & & & & & & & & & . & & 0 \\
\hline Deltek Systems & & & & & & & & & & & $\sqrt{ }$ & & 1 \\
\hline EMR Innovations & & & & & & & & & & & & & 0 \\
\hline Enhanced Systems \& Services & & & & & & & & & & & & & 0 \\
\hline Epicor & $\sqrt{ }$ & $\sqrt{ }$ & $\sqrt{ }$ & & & & & & & & 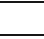 & & 3 \\
\hline eTek International & & & & & & & & & & & & & 0 \\
\hline Europa Telecom Group & $\sqrt{ }$ & & $\sqrt{ }$ & & & & $\sqrt{ }$ & $\sqrt{ }$ & $\sqrt{ }$ & & $\sqrt{ }$ & & 6 \\
\hline Evolucion e Inovacion Empresarial SC & $\sqrt{ }$ & & & & & & & & & & & & 1 \\
\hline EXEControl Global Solutions & & & & & & & & & & & & & 0 \\
\hline FlexiInternational & $\sqrt{ }$ & $\sqrt{ }$ & $\sqrt{ }$ & & & $\sqrt{ }$ & & & & & & & 4 \\
\hline Glovia International & & & & & & & & & & & & & 0 \\
\hline GMA Infosys & & & & & & & & & & & & & 0 \\
\hline IFS & & & & & & & & & & & & & 0 \\
\hline iLatina B2B Business Services & & & & & & & & & & & & & 0 \\
\hline Intacct Corp & & & & & & & & & & & & & 0 \\
\hline Intentia International & $\sqrt{ }$ & & $\sqrt{ }$ & & & & $\sqrt{ }$ & $\sqrt{ }$ & $\sqrt{ }$ & & $\sqrt{ }$ & & 6 \\
\hline Intuit & & & & & & & & & & & & & 0 \\
\hline IQMS & & & & & & & & & & & & & 0 \\
\hline iSoft & & & & & & & $\sqrt{ }$ & & & & & & 1 \\
\hline JDH Business Systems & & & & & & & & & & & & & 0 \\
\hline Maconomy, Inc & & & & & & & & & & $\sqrt{ }$ & & & 1 \\
\hline Made2Manage Systems & & & & & & & & & & & & & 0 \\
\hline Microsoft & $\sqrt{ }$ & $\sqrt{ }$ & $\sqrt{ }$ & & & $\sqrt{ }$ & $\sqrt{ }$ & $\sqrt{ }$ & $\sqrt{ }$ & & $\sqrt{ }$ & & 8 \\
\hline Mincom & & & & $\sqrt{ }$ & & & & & & & $\sqrt{ }$ & & 2 \\
\hline MYOB US & & & & & & & & & & & & & 0 \\
\hline NetSuite & & & & & & & & & & & & & 0 \\
\hline Open System, Inc & & & & & & & & & & & & & 0 \\
\hline Oracle & $\sqrt{ }$ & $\sqrt{ }$ & $\sqrt{ }$ & $\sqrt{ }$ & $\sqrt{ }$ & $\sqrt{ }$ & $\sqrt{ }$ & $\sqrt{ }$ & $\sqrt{ }$ & $\sqrt{ }$ & $\sqrt{ }$ & $\sqrt{ }$ & 12 \\
\hline QAD & & & & & & & & & & & & & 0 \\
\hline Ramco Systems & $\sqrt{ }$ & & $\sqrt{ }$ & & & & & & & & $\sqrt{ }$ & & 3 \\
\hline Red Wing Software, Inc. & & & & & & & & & & & & & 0 \\
\hline Relevant Business Systems & & & & & & & & & & & & & 0 \\
\hline Ross Systems & & & & & & & & & & & & & 0 \\
\hline Sage Software & & & & & & & $\sqrt{ }$ & & & & $\sqrt{ }$ & & 2 \\
\hline SAP & $\sqrt{ }$ & & $\sqrt{ }$ & $\sqrt{ }$ & $\sqrt{ }$ & & $\sqrt{ }$ & & $\sqrt{ }$ & $\sqrt{ }$ & $\sqrt{ }$ & $\sqrt{ }$ & 9 \\
\hline SYSPRO & & & & & & & & & & & & & 0 \\
\hline Tailor Made Systems (TMS) & & & & & & & & & & & & & 0 \\
\hline Verticent & & & & & & & & & & & & & 0 \\
\hline Vigilant Business Software, Inc. & & & & & & & & & & & $\sqrt{ }$ & & 1 \\
\hline Ceecom, Inc. & & & & & & & & & & & & & 0 \\
\hline $\mathrm{i} 2$ & & & & & & & & & & & & & 0 \\
\hline IFS & & & & & & & & & & & & & 0 \\
\hline ProfitKey International & & & & & & & & & & & & & 0 \\
\hline Technology Group International & & & & & & & & & & & & & 0 \\
\hline Eshbel & & & & & & & $\sqrt{ }$ & & & & $\sqrt{ }$ & & 2 \\
\hline IBM & $\sqrt{ }$ & $\sqrt{ }$ & $\sqrt{ }$ & & & $\sqrt{ }$ & $\sqrt{ }$ & $\sqrt{ }$ & $\sqrt{ }$ & $\sqrt{ }$ & $\sqrt{ }$ & & 9 \\
\hline
\end{tabular}

Table 11. ERP producers and business operations from group Financial and Public Services. 


\begin{tabular}{|c|c|c|c|c|c|c|c|c|c|c|c|c|c|c|c|c|c|c|c|c|c|c|c|c|c|c|c|c|c|c|c|c|c|c|c|c|}
\hline Producer & & & & & & & & & & & & & & & & Ian & ufa & act & tur & ing & & & & & & & & & & & & & & & & TOTAL \\
\hline Producer & 13 & 14 & & 16 & 17 & & 19 & 20 & & 22 & 23 & & 25 & & & & & & & 32 & & 34 & & 36 & 373 & 38 & & 40 & 41 & & & & & 46 & 47 & 1OIAL \\
\hline 3i Infotech & & & & & & & & & & & & & & & & & & & & & & & & & & & & & & & & & & & & 0 \\
\hline Add+On Software & & & & & & & & & & & & & & & & & & & & & & & & & & & & & & & & & & & & 0 \\
\hline Advanced Software Development Corp & & & & & & & & & & & & & & & & & & & & & & & & & & & & & & & & & & & & 0 \\
\hline American Business Systems, Inc. & & & & & & & & & & & & & & & & & & & & & & & & & & & & & & & & & & & & 0 \\
\hline Aperum (novo ime infor) & $\sqrt{ }$ & & $\sqrt{ }$ & $\sqrt{ }$ & $\sqrt{ }$ & $\sqrt{ }$ & $\sqrt{ }$ & $\sqrt{ }$ & & $\sqrt{ }$ & $\sqrt{1}$ & $\sqrt{ }$ & $\sqrt{ }$ & $\sqrt{ }$ & & $\sqrt{ }$ & $\sqrt{1}$ & $\sqrt{ }$ & $\sqrt{ }$ & $\sqrt{ }$ & $\sqrt{ }$ & & & & $\sqrt{ }$ & & & $\sqrt{ }$ & $\sqrt{ }$ & & & & & & & 21 \\
\hline BatchMaster Software Inc & & & & & & & $\sqrt{ }$ & & & & $\sqrt{ }$ & & $\sqrt{1}$ & $\sqrt{ }$ & & & & & & & $\sqrt{ }$ & & & & & & & & & & & & & & & 5 \\
\hline Cedar Group & & & & & & & & & & & & & & & $\sqrt{ }$ & & & & & & & & & & & & & & & & & & & & & 1 \\
\hline Cincom Systems & & & & & & & & & & & & & & & & & & & & & & & & & & & & & & & & & & & & 0 \\
\hline CMS Manufacturing Systems, Inc & $\sqrt{ }$ & & $\sqrt{ }$ & $\sqrt{ }$ & & & & & & $\sqrt{ }$ & & $\sqrt{1}$ & $\sqrt{ }$ & $\sqrt{ }$ & & $\sqrt{1}$ & $\sqrt{1}$ & $\sqrt{ }$ & & & & & & & $\sqrt{ }$ & & & $\sqrt{1}$ & & & & & & & & 12 \\
\hline COSS Systems & $\sqrt{ }$ & & & $\sqrt{ }$ & & & & & & & & & & & & & & & & $\sqrt{1}$ & & & & & $\sqrt{1}$ & $\sqrt{1}$ & & & $\sqrt{1}$ & & & & $\sqrt{1}$ & & & 7 \\
\hline Cougar Mountain Software & & & & & & & & & & & & & & & & & & & & & & & & & & & & & & & & & & & & 0 \\
\hline CSB-System & & & & & & & $\sqrt{1}$ & & & & $\sqrt{ }$ & & $\sqrt{ }$ & $\sqrt{1}$ & & & & & & & $\sqrt{1}$ & & & & & & & & & & & & & & & 5 \\
\hline CYMA & & & & & & & & & & & & & & & & & & & & & & & & & & & & & & & & & & & & 0 \\
\hline Datacor & & & & & & & $\sqrt{1}$ & & & & & & 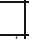 & & & & & & & & & & & & & & & & & & & & & & & 1 \\
\hline Datamodes & & & & & & & $\sqrt{ }$ & & & & & & $\sqrt{ }$ & & & & & & & & $\sqrt{ }$ & & & & & & & & & & & & & & & 3 \\
\hline Deltek Systems & $\sqrt{ }$ & & & & & & & & & & & & & & $\sqrt{ }$ & & & & $\sqrt{ }$ & & & & & & & & & & & & & & & & & 3 \\
\hline EMR Innovations & & & & & & & $\sqrt{ }$ & & & & $\sqrt{1}$ & & $\sqrt{1}$ & $\sqrt{1}$ & & & & & & & $\sqrt{1}$ & & & & & & & & & & & & & & & 5 \\
\hline Enhanced Systems \& Services & $\sqrt{1}$ & & & & & & & $\sqrt{1}$ & & & & & & & $\sqrt{ }$ & & & & & & & & $\sqrt{1}$ & & $\sqrt{ }$ & & & & & & & & & & & 5 \\
\hline Epicor & & & & & & & & & & & & & & & & & & & & & & & & & & & & & & & & & & & & 0 \\
\hline eTek International & & & & & & & & & & & & & & & $\sqrt{ }$ & & & & & & & & & & & & & & & & & & & & & 1 \\
\hline Europa Telecom Group & & & & & & & & & & & & & & & & & & & & & & & & & & & & & $\sqrt{1}$ & & & & & & & 1 \\
\hline Evolucion e Inovacion Empresarial SC & & & & & & & & & & & & & & & & & & & & & & & & & & & & & & & & & & & & 0 \\
\hline EXEControl Global Solutions & & & & & & & & & & & & & & & & & & & & & & & & & & & & & & & & & & & & 0 \\
\hline FlexiInternational & & & & & & & & & & & & & & & & & & & & & & & & & & & & & & & & & & & & 0 \\
\hline Glovia International & & & & $\sqrt{ }$ & & & & & & & & & & & & $\sqrt{1}$ & $\sqrt{1}$ & $\sqrt{ }$ & & $\sqrt{1}$ & & & & & & & & & & & & & & & & 5 \\
\hline GMA Infosys & & & & & & & & & & & & & & & & & & & & & & & & & & & & & & & & & & & & 0 \\
\hline IFS & $\sqrt{ }$ & $\sqrt{1}$ & $\sqrt{ }$ & $\sqrt{ }$ & $\sqrt{1}$ & $\sqrt{1}$ & $\sqrt{1}$ & $\sqrt{1}$ & & & $\sqrt{1}$ & & $\sqrt{1}$ & & $\sqrt{1}$ & $\sqrt{1}$ & $\sqrt{6}$ & $\sqrt{ }$ & & $\sqrt{1}$ & $\sqrt{ }$ & & $\sqrt{1}$ & & $\sqrt{ }$ & & & $\sqrt{1}$ & $\sqrt{1}$ & $\sqrt{ }$ & & & & & $\sqrt{1}$ & 22 \\
\hline iLatina B2B Business Services & & & & & & & & & & & & & & & & & & & & & & & & & & & & & & & & & & & $\sqrt{ }$ & 1 \\
\hline Intacct Corp & & & & & & & & & & & & & & & & & & & & & & & & & & & & & & & & & & & & 0 \\
\hline Intentia International & $\sqrt{1}$ & & $\sqrt{ }$ & $\sqrt{ }$ & & & $\sqrt{1}$ & & & $\sqrt{ }$ & $\sqrt{1}$ & $\sqrt{1}$ & $\sqrt{ }$ & & & & $\sqrt{1}$ & $\sqrt{ }$ & & $\sqrt{1}$ & $\sqrt{ }$ & & $\sqrt{1}$ & & $\sqrt{ }$ & $\sqrt{1}$ & & $\sqrt{1}$ & $\sqrt{1}$ & & $\sqrt{ }$ & $\sqrt{ }$ & & $\sqrt{ }$ & $\sqrt{ }$ & 21 \\
\hline Intuit & & & & & & & & & & & & & & & $\sqrt{1}$ & & & & & & & & & & & & & t & & & & & & & & 1 \\
\hline IQMS & & & & $\sqrt{ }$ & & & & & & & & & & & & & & & & & & & $\sqrt{1}$ & & & & & $\sqrt{ }$ & & & & & & & & 3 \\
\hline iSoft & & & & & & & & & & & & & & & & & & & & & & & & & & & & & & & & & & & & 0 \\
\hline JDH Business Systems & & & & $\sqrt{ }$ & & & & & & & & & & & $\sqrt{ }$ & & & & & & & & & & $\sqrt{ }$ & & $\sqrt{ }$ & & & & & & & & & 4 \\
\hline Maconomy, Inc & & & & & & & & & & & & & & & & & & & & & & & & & & & & & & & & & & & & 0 \\
\hline Made2Manage Systems & $\sqrt{ }$ & & & & & & & & & & & & & & & & $\sqrt{ }$ & $\sqrt{ }$ & & $\sqrt{ }$ & & & & & $\sqrt{ }$ & & & $\sqrt{1}$ & $\sqrt{ }$ & & & & & & & 7 \\
\hline Microsoft & & & & $\sqrt{ }$ & $\sqrt{ }$ & $\sqrt{ }$ & $\sqrt{ }$ & & & $\sqrt{ }$ & $\sqrt{ }$ & $\sqrt{ }$ & $\sqrt{1}$ & & & $\sqrt{ }$ & & & $\sqrt{ }$ & & $\sqrt{ }$ & & & & & & & & & & & & & & $\sqrt{ }$ & 12 \\
\hline Mincom & $\sqrt{ }$ & & $\sqrt{ }$ & $\sqrt{ }$ & $\sqrt{ }$ & & & & & & & & & & & $\sqrt{ }$ & & & & & & & & & $\sqrt{ }$ & & & & $\sqrt{1}$ & & & & & $\sqrt{ }$ & & 8 \\
\hline MYOB US & & & & & & & & & & & & & & & & & & & & & & & & & & & & & & & & & & & & 0 \\
\hline NetSuite & & & & & & & & & $\sqrt{ }$ & & & & & & & & & & & & & & & & & & & & & & & & & & & 1 \\
\hline Open System, Inc & & & & & & & & & & & & & & & & & & & & & & & & & & & & & & & & & & & & 0 \\
\hline Oracle & $\sqrt{ }$ & $\sqrt{ }$ & $\sqrt{ }$ & $\sqrt{1}$ & $\sqrt{1}$ & $\sqrt{1}$ & $\sqrt{ }$ & & & $\sqrt{ }$ & $\sqrt{ }$ & $\sqrt{1}$ & $\sqrt{ }$ & $\sqrt{1}$ & $\sqrt{1}$ & $\sqrt{1}$ & $\sqrt{ }$ & $\sqrt{ }$ & & $\sqrt{1}$ & $\sqrt{1}$ & $\sqrt{ }$ & $\sqrt{ }$ & $\sqrt{ }$ & $\sqrt{ }$ & $\sqrt{1}$ & $\sqrt{ }$ & $\sqrt{1}$ & $\sqrt{1}$ & $\sqrt{ }$ & $\sqrt{ }$ & & $\sqrt{ }$ & $\sqrt{ }$ & $\sqrt{ }$ & 31 \\
\hline QAD & & & & $\sqrt{ }$ & & & & & & $\sqrt{ }$ & $\sqrt{1}$ & $\sqrt{1}$ & $\sqrt{ }$ & $\sqrt{1}$ & & $\sqrt{1}$ & $\sqrt{-}$ & $\sqrt{ }$ & & $\sqrt{ }$ & $\sqrt{ }$ & & & & $\sqrt{ }$ & & & & $\sqrt{1}$ & & & & T & & - & 13 \\
\hline Ramco Systems & & & $\sqrt{ }$ & & & & $\sqrt{ }$ & & & & $\sqrt{1}$ & & $\sqrt{1}$ & & & & & & & & & & & & $\sqrt{ }$ & & & & $\sqrt{1}$ & & & & & & $\sqrt{1}$ & 7 \\
\hline Red Wing Software, Inc. & & & & & & & & & $\sqrt{ }$ & & & & & & & & & & & & & & & & & & & & & & & & & & & 1 \\
\hline Relevant Business Systems & $\sqrt{ }$ & & $\sqrt{ }$ & & & & & & & & & & & & $\sqrt{1}$ & & & & & & & & & & & & & & & & & & & & & 3 \\
\hline Ross Systems & & & & & & & $\sqrt{1}$ & & & & $\sqrt{ }$ & $\sqrt{1}$ & $\sqrt{1}$ & $\sqrt{1}$ & & & & & & & $\sqrt{1}$ & $\sqrt{1}$ & & $\sqrt{1}$ & $\sqrt{ }$ & & $\sqrt{1}$ & & $\sqrt{1}$ & & & & $\sqrt{1}$ & & & 12 \\
\hline Sage Software & & & & & & & & & & & & & & & $\sqrt{ }$ & & & & & & & & & & & & & & & & & & & & & 1 \\
\hline SAP & $\sqrt{ }$ & $\sqrt{1}$ & $\sqrt{ }$ & $\sqrt{ }$ & $\sqrt{ }$ & $\sqrt{ }$ & $\sqrt{ }$ & & & $\sqrt{ }$ & $\sqrt{ }$ & $\sqrt{ }$ & $\sqrt{ }$ & $\sqrt{1}$ & $\sqrt{ }$ & $\sqrt{ }$ & $\sqrt{1}$ & $\sqrt{ }$ & $\sqrt{ }$ & $\sqrt{1}$ & $\sqrt{ }$ & $\sqrt{ }$ & $\sqrt{ }$ & $\sqrt{ }$ & $\sqrt{ }$ & $\sqrt{1}$ & $\sqrt{ }$ & $\sqrt{ }$ & $\sqrt{1}$ & $\sqrt{ }$ & $\sqrt{ }$ & & $\sqrt{ }$ & $\sqrt{ }$ & $\sqrt{ }$ & 32 \\
\hline SYSPRO & $\sqrt{ }$ & & $\sqrt{ }$ & $\sqrt{ }$ & & & $\sqrt{ }$ & & & $\sqrt{ }$ & $\sqrt{ }$ & $\sqrt{1}$ & $\sqrt{ }$ & $\sqrt{1}$ & & $\sqrt{ }$ & $\sqrt{1}$ & $\sqrt{ }$ & & $\sqrt{ }$ & $\sqrt{ }$ & & $\sqrt{ }$ & & $\sqrt{ }$ & & & $\sqrt{ }$ & $\sqrt{ }$ & & & $\sqrt{ }$ & & & & 19 \\
\hline Tailor Made Systems (TMS) & & & & & & & & & & & & & & & & & & & & & & & & & & & & & & & & & & & & 0 \\
\hline Verticent & & & & & & & & & & & & & & & & & & & & & & & & & $\sqrt{ }$ & & & & $\sqrt{1}$ & & & & & & & 2 \\
\hline Vigilant Business Software, Inc. & & & & & & & & & & & & & & & & & & & & & & & & & & & & & & & & & & & & 0 \\
\hline Ceecom, Inc. & & & & & & & & & & $\sqrt{ }$ & $\sqrt{ }$ & & $\sqrt{ }$ & & $\sqrt{1}$ & $\sqrt{ }$ & $\sqrt{1}$ & $\sqrt{ }$ & & & $\sqrt{ }$ & & & & & & & & & & & & & & & 8 \\
\hline i2 & $\sqrt{ }$ & & & $\sqrt{ }$ & & & & & & $\sqrt{ }$ & $\sqrt{1}$ & $\sqrt{1}$ & $\sqrt{1}$ & $\sqrt{1}$ & & $\sqrt{1}$ & $\sqrt{1}$ & $\sqrt{ }$ & & $\sqrt{1}$ & & & & & $\sqrt{ }$ & & & & $\sqrt{1}$ & & & & & & & 13 \\
\hline IFS & $\sqrt{ }$ & $\sqrt{ }$ & $\sqrt{ }$ & $\sqrt{ }$ & $\sqrt{1}$ & $\sqrt{ }$ & $\sqrt{ }$ & $\sqrt{1}$ & & & $\sqrt{1}$ & & $\sqrt{1}$ & & $\sqrt{1}$ & $\sqrt{1}$ & $\sqrt{1}$ & $\sqrt{ }$ & & $\sqrt{1}$ & $\sqrt{1}$ & & $\sqrt{1}$ & & $\sqrt{1}$ & & & $\sqrt{1}$ & $\sqrt{1}$ & $\sqrt{1}$ & & & & & $\sqrt{ }$ & 22 \\
\hline ProfitKey International & $\sqrt{ }$ & & & $\sqrt{ }$ & & & & & & & - & & $-5+2>$ & & & $\sqrt{ }$ & $\sqrt{1}$ & $\sqrt{ }$ & & & 正 & & $\sqrt{1}$ & & & & & & & & & & & & & 6 \\
\hline Technology Group International & & & & & & & $\sqrt{1}$ & & $\sqrt{ }$ & & $\sqrt{ }$ & $\sqrt{1}$ & $\sqrt{1}$ & $\sqrt{1}$ & $\sqrt{1}$ & $\sqrt{1}$ & $\sqrt{1}$ & $\sqrt{ }$ & & & & $\sqrt{1}$ & & & & & & & & & & & & & & 11 \\
\hline Eshbel & $\sqrt{ }$ & & $\sqrt{ }$ & $\sqrt{ }$ & $\sqrt{ }$ & $\sqrt{ }$ & $\sqrt{ }$ & & & $\sqrt{ }$ & & $\sqrt{1}$ & & & $\sqrt{1}$ & $\sqrt{1}$ & $\sqrt{ }$ & $\sqrt{ }$ & & & & & $\sqrt{ }$ & & & & & & & & $\sqrt{ }$ & & & & & 14 \\
\hline IBM & $\sqrt{ }$ & $\sqrt{1}$ & $\sqrt{1}$ & $\sqrt{1}$ & $\sqrt{1}$ & $\sqrt{1}$ & $\sqrt{1}$ & & & $\sqrt{1}$ & $\sqrt{1}$ & $\sqrt{1}$ & $\sqrt{1}$ & $\sqrt{1}$ & 5 & $\sqrt{1}$ & $\sqrt{1}$ & $\sqrt{1}$ & $\sqrt{1}$ & & $\sqrt{1}$ & $\sqrt{1}$ & & & & & & & & & & & & & $\sqrt{1}$ & 19 \\
\hline
\end{tabular}

Table 12. ERP producers and business operations from group Manufacturing. 


\begin{tabular}{|c|c|c|c|c|c|c|c|c|c|c|c|c|c|c|c|c|c|c|c|c|c|c|c|c|}
\hline \multirow{2}{*}{ Producer } & \multicolumn{23}{|c|}{ Service } & \multirow{2}{*}{ TOTAL } \\
\hline & 48 & 49 & 50 & 515 & \begin{tabular}{|l|l}
52 & 5 \\
\end{tabular} & 53 & \begin{tabular}{|l|l|l}
54 & 5 \\
\end{tabular} & 55 & 56 & 57 & 58 & 59 & 60 & 61 & 62 & 63 (6) & 64 & \begin{tabular}{|l|l}
65 & 6 \\
\end{tabular} & \begin{tabular}{l|l}
66 & 6 \\
\end{tabular} & \begin{tabular}{l|l}
67 & 6 \\
\end{tabular} & \begin{tabular}{l|l}
68 & 6 \\
\end{tabular} & \begin{tabular}{l|l}
69 & 7 \\
\end{tabular} & 70 & \\
\hline 3 i Infotech & & & & & & & & & & & & & & & & & & & & & & & & 0 \\
\hline Add+On Software & & & & & & & & & & & & & & & & & & & & & & & $\sqrt{ }$ & 1 \\
\hline Advanced Software Development Corp & & & & & & & & & $\sqrt{ }$ & & & & $\sqrt{ }$ & & & & & & & & & & & 2 \\
\hline American Business Systems, Inc. & & & & & & & & & & $\sqrt{ }$ & & & & & & & & & & & & & $\sqrt{ }$ & 2 \\
\hline Aperum (novo ime infor) & & & & & & & & & & $\sqrt{ }$ & $\sqrt{ }$ & & & $\sqrt{ }$ & & $\sqrt{ }$ & & & $\sqrt{ }$ & & & \begin{tabular}{l|l}
$\sqrt{1}$ & 1 \\
\end{tabular} & $\sqrt{ }$ & 7 \\
\hline BatchMaster Software Inc & & & & & & & & & & & & & & & & & & & & & & & & 0 \\
\hline Cedar Group & & & & & & & & & & $\sqrt{ }$ & & $\sqrt{ }$ & & $\sqrt{ }$ & & & & & & & & & & 3 \\
\hline Cincom Systems & & & & & & & & & & $\sqrt{ }$ & & $\sqrt{ }$ & & & & $\sqrt{ }$ & & & & & & & & 3 \\
\hline CMS Manufacturing Systems, Inc & & & & & & & & & & & & & & & & & & & & & & & & 0 \\
\hline COSS Systems & & & $\sqrt{ }$ & $\sqrt{ }$ & $\sqrt{ }$ & & & & & & & & & & & & & & & & & & & 3 \\
\hline Cougar Mountain Software & & & & & & & & & & $\sqrt{ }$ & & $\sqrt{ }$ & & & & & & & & & & & & 2 \\
\hline CSB-System & $\sqrt{ }$ & & & & & & & & & $\sqrt{ }$ & & & & & & & & & & & & & & 2 \\
\hline CYMA & & & & & & & & & & & & $\sqrt{ }$ & & & & & & & & & & & & 1 \\
\hline Datacor & & & & & & & & & & & & & & & & & & & & & & & & 0 \\
\hline Datamodes & & & & & & & & & & & & & & & & & & & & & & & $\sqrt{ }$ & 1 \\
\hline Deltek Systems & & & & & & & $\sqrt{ }$ & & & & & $\sqrt{ }$ & & & & & & & & & & & & 2 \\
\hline EMR Innovations & & & & & & & & & & & & & & & & & & & & & & & & 0 \\
\hline Enhanced Systems \& Services & $\sqrt{ }$ & & & & & & & & & & & & & & & & $\sqrt{ }$ & & & & & & & 2 \\
\hline Epicor & & & & & & & $\sqrt{ }$ & & & & & $\sqrt{ }$ & & $\sqrt{ }$ & & & & $\sqrt{ }$ & & & & & $\sqrt{ }$ & 5 \\
\hline eTek International & & & & & & & $\sqrt{ }$ & & & & & & & & & & & & & & & & $\sqrt{ }$ & 2 \\
\hline Europa Telecom Group & & & & & & & & & & & & & & & & $\sqrt{ }$ & & & & & & & & 1 \\
\hline Evolucion e Inovacion Empresarial SC & & & & & & & & & & & & & & & & & & & & & & & & 0 \\
\hline EXEControl Global Solutions & & & & & & & $\sqrt{ }$ & & & & & & $\sqrt{ }$ & . & & 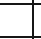 & & $\sqrt{ }$ & & & & & $\sqrt{ }$ & 4 \\
\hline FlexiInternational & & & & & & & $\sqrt{ }$ & & & & & & & $\sqrt{ }$ & & & & & & & & & & 2 \\
\hline Glovia International & & & & & & & $\sqrt{ }$ & & & & & & & & & $\sqrt{ }$ & & & & & & & & 2 \\
\hline GMA Infosys & & & & & & & & & & & & & & & & & & & & & & & $\sqrt{ }$ & 1 \\
\hline IFS & $\sqrt{ }$ & & & & & & $\sqrt{ }$ & $\sqrt{ }$ & & & & & & & & $\sqrt{1}$ & $\sqrt{ }$ & & $\sqrt{ }$ & $\sqrt{ }$ & & $\sqrt{ }$ & & 8 \\
\hline iLatina B2B Business Services & & & & & & & & & & & & & & & & & & & & & & & & 0 \\
\hline Intacct Corp & & & & & & & $\sqrt{ }$ & & & $\sqrt{ }$ & & $\sqrt{ }$ & & $\sqrt{ }$ & & & & 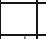 & & & & & $\sqrt{ }$ & 5 \\
\hline Intentia International & $\sqrt{ }$ & & & & & & & & & & & & $\sqrt{ }$ & & & & & $\sqrt{ }$ & & & & & $\sqrt{ }$ & 4 \\
\hline Intuit & & & & & & & $\sqrt{ }$ & & & & & $\sqrt{ }$ & & & $\sqrt{ }$ & & & $\sqrt{ }$ & & & & & $\sqrt{ }$ & 5 \\
\hline IQMS & & & & & & & & & & & & & & & & & & & & & & & & 0 \\
\hline iSoft & & & & & & & & & & & & & & & & & & & & & & & & 0 \\
\hline JDH Business Systems & & & & & & & & & & & & & $\sqrt{ }$ & & & & & & & & & & $\sqrt{ }$ & 2 \\
\hline Maconomy, Inc & & & & & & & $\sqrt{ }$ & & & & & $\sqrt{ }$ & & & & & & & & & & & & 2 \\
\hline Made2Manage Systems & & & & & & & $\sqrt{ }$ & & & & & & & & & & & & & & & & & 1 \\
\hline Microsoft & & $\sqrt{ }$ & $\sqrt{ }$ & & $\sqrt{ }$ & & $\sqrt{ }$ & & & 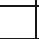 & & & & $\sqrt{ }$ & & & $\sqrt{ }$ & $\sqrt{ }$ & $\sqrt{ }$ & & & & $\sqrt{ }$ & 9 \\
\hline Mincom & $\sqrt{ }$ & & & & & & & $\sqrt{ }$ & & $\sqrt{ }$ & & & & & & & & & $\sqrt{ }$ & & & & & 4 \\
\hline MYOB US & & & & & & & & & & & & & & & & & & & & & & & $\sqrt{ }$ & 1 \\
\hline NetSuite & & & & & & & $\sqrt{ }$ & & & $\sqrt{ }$ & & $\sqrt{ }$ & & $\sqrt{ }$ & & & & $\sqrt{ }$ & & & & & $\sqrt{ }$ & 6 \\
\hline Open System, Inc & & & & & & & $\sqrt{ }$ & & & $\sqrt{ }$ & & $\sqrt{ }$ & & & & & & & & & & & $\sqrt{ }$ & 4 \\
\hline Oracle & & $\sqrt{ }$ & $\sqrt{ }$ & $\sqrt{ }$ & $\sqrt{ }$ & & $\sqrt{ }$ & & & & & & & & & $\sqrt{ }$ & & $\sqrt{1}$ & $\sqrt{ }$ & $\sqrt{ }$ & $\sqrt{ }$ & $\sqrt{ }$ & & 11 \\
\hline QAD & & & & & & & & & & & & & & & & & & & & & & & & 0 \\
\hline Ramco Systems & $\sqrt{ }$ & & & & & & & & & $\sqrt{ }$ & & & & & & & & & & & & & $\sqrt{ }$ & 3 \\
\hline Red Wing Software, Inc. & & & & & & & & & & & & & & & & & & & & & & & & 0 \\
\hline Relevant Business Systems & & & & & & & $\sqrt{ }$ & & & & & & & & & & & & & & & & & 1 \\
\hline Ross Systems & & & & & & & & & & & & & & & & & & & & & & & & 0 \\
\hline Sage Software & & & & & & & $\sqrt{ }$ & & & & & $\sqrt{ }$ & & & $\sqrt{ }$ & & & & & & & & $\sqrt{ }$ & 4 \\
\hline SAP & $\sqrt{ }$ & $\sqrt{ }$ & $\sqrt{ }$ & $\sqrt{ }$ & $\sqrt{ }$ & $\sqrt{ }$ & $\sqrt{ }$ & $\sqrt{ }$ & & $\sqrt{ }$ & & & & & & $\sqrt{ }$ & $\sqrt{ }$ & $\sqrt{ }$ & $\sqrt{ }$ & & & $\sqrt{ }$ & $\sqrt{ }$ & 15 \\
\hline SYSPRO & & & & & & & $\sqrt{ }$ & & & & & & & & & & & & & & & & $\sqrt{ }$ & 2 \\
\hline Tailor Made Systems (TMS) & & & & $\sqrt{ }$ & $\sqrt{ }$ & & & & & & & & & & & & & & & & & & $\sqrt{ }$ & 3 \\
\hline Verticent & & & & & & & & & & & & & & & & & & & & & & & & 0 \\
\hline Vigilant Business Software, Inc. & & & & & & & & & & $\sqrt{ }$ & & & & & & & & & & & & & $\sqrt{ }$ & 2 \\
\hline Ceecom, Inc. & & & & & & & & & & & & & & & & & & & & & & & $\sqrt{ }$ & 1 \\
\hline 12 & $\sqrt{ }$ & & & & & & & & & $\sqrt{ }$ & & & & & & & & & & & & & & 2 \\
\hline IFS & $\sqrt{ }$ & & & & & & $\sqrt{ }$ & $\sqrt{ }$ & & & & & & & & $\sqrt{ }$ & $\sqrt{ }$ & & $\sqrt{1}$ & $\sqrt{ }$ & & $\sqrt{ }$ & & 8 \\
\hline ProfitKey International & & & & & & & & & & & & & & & & & & & & & & & & 0 \\
\hline Technology Group International & & & & & & & & & & & & & & & & & & & & & & & $\sqrt{ }$ & 1 \\
\hline Eshbel & & & & & & & $\sqrt{ }$ & & & $\sqrt{ }$ & $\sqrt{ }$ & & & & & $\sqrt{ }$ & & & & & & & & 4 \\
\hline IBM & & $\sqrt{1}$ & $\sqrt{1}$ & $\sqrt{ }$ & $\sqrt{ }$ & & & $\sqrt{ }$ & & $\sqrt{ }$ & & & & & & $\sqrt{1}$ & $\sqrt{ }$ & $\sqrt{1}$ & $\sqrt{ }$ & & & & $\sqrt{ }$ & 11 \\
\hline
\end{tabular}

Table 13. ERP producers and business operations from group Service. 


\section{References}

[1] Abas Business Software (2004), ERP Survey 2003/2004., ftp://ftp.abas.de/pub/ marketing/download/eng_konradin2003.pdf (current November 18., 2007).

[2] C. КосH (2008), The ABCs of ERP, http://www.cio.com/article/40323 (current March 22., 2008.)

[3] Carnet (2007), Open Source, http: //www. carnet.hr/tematski/opensource /naslovnica (current November 18., 2007).

[4] Center for Economic Options (2005), http://www. centerforeconomicoptions.org /documents/WhydoIneedabusinesslicense 000. doc (current November 18., 2007).

[5] Eurostat (2007), http://ec.europa.eu/ eurostat/ramon/index.cfm?TargetUrl=DSP PUB_WELC (current November 18., 2007).

[6] IDC, The Integrated Enterprise Resource Management Software Application Market in Croatia, 1999-2004, IDC East Central Europe, Praha, 2000.

[7] K. Fertalu, D. Kalpić, ERP Software Evaluation and Comparative Analysis, Journal of Computing and Information Technology - CIT (12) 3 September 2004, pp. 195-209.

[8] M. BuRnS, Accounting System/ERP Customer Survey, 2006, http: //www . 180systems . com/ERPCustomer Survey .php (current November 18., 2007).

[9] M. BuRns, Accounting/ERP Comparison, 2006, http: //www.180systems . com/ERPsystemcomparison.php (current November 18., 2007).

[10] M. Maitland, D. M. Blitzer, A GICS Overview for Standard \& Poor's U.S. Indices, 2002, wWw2. standardandpoors. com/spf/pdf/index /GICSIndexDocument.PDF (current November 18., 2007).

[11] Microsoft (2007), http://www.microsoft.com/business/ default.mspx (current February 10., 2007).

[12] On-Line Consultant, Top ERP Vendors, 2007, http://www.health-infosys-dir.com/ top $\% 20$ ERP\%20vendors.htm (current May 2., 2007.)

[13] P. SIKAVICA, M. NovAK, Poslovna organizacija, Zagreb: Informator, 1993.

[14] Quebec Inc. (2007), http://templates.rfpbuilder.com/ERP1/ERPvendors.htm (current May 2., 2007.)

[15] $\operatorname{SAP}(2007)$, http://www.sap.com/industries/index .epx (current February 10., 2007).
[16] Software Finder (2007), http://softwarefinder.mbtmag.com (current May 2., 2007.)

[17] V. VuKšić BosilJ, M. SPREMIć, ERP System Implementation and Business Process Change: Case Study of a Pharmaceutical Company, Journal of Computing and Information Technology - CIT (13)1 March 2005, pp. 11-24.

[18] L. VON BERTALANFFY, General systems theory: Foundations, Development and Applications, New York, Braziller, 1968.

Received: April, 2008 Revised: January, 2009 Accepted: February, 2009

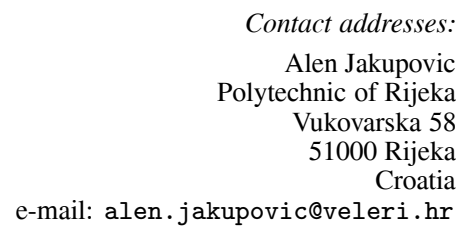

Mile Pavlic Department of Informatics University of Rijeka Omladinska 14 51000 Rijeka Croatia

e-mail: mile.pavlic@ffri.hr

Kresimir Fertalj Faculty of Electrical Engineering and Computing University of Zagreb

Department of Applied Computing Unska 3 10000 Zagreb Croatia

e-mail: kresimir.fertalj@fer.hr

ALEN JAKUPOVIC received his M. Sc. degree in 2006 in information science from the Faculty of Organization and Informatics, University of Zagreb, Croatia. He is a professor at Business Department of the Polytechnic of Rijeka. His work focuses on the information systems design methodology and measurement.

MILE PAVLIC is a professor of IS and data modelling on the Department of Informatics at the University of Rijeka. He is the author of 5 books and over 40 journal articles. His work focuses on the following methods: business system analysis, business process modelling, data modelling and software engineering.

KRESIMIR FERTALJ is an associate professor at the Department of Applied Computing at the Faculty of Electrical Engineering and Computing, University of Zagreb. Currently he lectures a couple of undergraduate and postgraduate courses in computing. His professional and scientific interest is in computer-aided software engineering, complex information systems and in project management. He has written over 70 scientific and professional publications and participated in conferences locally and abroad. He participated in a number of information system designs, implementations and evaluations. Fertalj is member of ACM, IEEE and PMI. 